Article

\title{
Springback Reduction of L-Shaped Part Using Magnetic Pulse Forming
}

\author{
Xiaohui Cui ${ }^{1,2,3, * \mathbb{C}}$, Ang Xiao ${ }^{2}$, Zhihao Du ${ }^{2}$, Ziqin Yan ${ }^{1}$ and Hailiang Yu ${ }^{1,2,3} \mathbb{C}$ \\ 1 Light Alloy Research Institute, Central South University, Changsha 410083, China; yzq1172@163.com (Z.Y.); \\ yuhailiang@csu.edu.cn (H.Y.) \\ 2 College of Mechanical and Electrical Engineering, Central South University, Changsha 410083, China; \\ xiaoang@csu.edu.cn (A.X.); dzh7695782@126.com (Z.D.) \\ 3 State Key Laboratory of High Performance Complex Manufacturing, Central South University, Changsha \\ 410083, China \\ * Correspondence: cuixh622@csu.edu.cn; Tel.: +86-1538-802-8791
}

Received: 20 February 2020; Accepted: 16 March 2020; Published: 18 March 2020

check for updates

\begin{abstract}
This study proposes an electromagnetic-assisted stamping (EMAS) method with magnetic-force loading at the sheet end in order to control the springback phenomenon. The new method does not change the structure of the mold and does not generate a magnetic force at the sheet corner compared to traditional EMAS. Thus, the new approach could greatly extend the mold lifespan and could be readily adopted in commercial production environments. The effects of technological parameters, such as the distance between the blank holder and die, discharge voltage, and sheet thickness on the springback phenomenon were analyzed. Our results suggest that tangential stress and elastic strain energy both decrease with the increase of discharge voltage. The simulation method accurately predicted the deformation of the sheet during the quasi-static stamping and dynamic magnetic forming processes. The simulation and experimental results both show that as the discharge voltage increases, the bent angle after springback decreases.
\end{abstract}

Keywords: electromagnetic-assisted stamping; coupled magnetic-structural analysis; springback control

\section{Introduction}

Sheet metal forming is an important processing method that is widely used in the automotive, aerospace, shipbuilding, and electrical industries. The method uses a mold to plastically deform sheets in order to obtain the parts in the required shape. The springback phenomenon is a common problem in sheet forming. After the mold is unloaded, springback redistributes internal stresses within the sheet and can greatly affect dimensional accuracy. Moreover, exceeding the allowable springback tolerance can lead to defects that prevent the accurate assembly of parts.

Some methods for controlling springback include mold compensation, pressure correction, stretch bending, and electroplasticity-assisted bending. The mold compensation method relies on the expertise of the engineer who performs certain tests and repairs the mold accordingly. This increases the cost of the mold, and forming efficiency is low. Pressure correction methods reduce the thickness of the sheet-bending region; however, the required press tonnage is significantly larger. With stretch bending, applying a much larger tensile stress to the sheet can reduce the springback effect, but this also exacerbates the thinning of the sheet. In the field of electrically-assisted forming, Egea et al. [1,2] proved that electrically-assisted bending is effective to reduce the bending force and the elastic restoring force during the bending process [1]. Moreover, the electrically-assisted wire-drawing process is feasible to enhance the material formability compared to the conventional wire-drawing process. 
The springback is related to the thickness, yield strength, and elastic modulus of sheet metal. The smaller the thickness and elastic modulus of the sheet, the greater the springback that occurs. The elastic modulus of aluminum alloy is one-third of that for steel. Thus, high springback easily appears on aluminum alloy. Electromagnetic forming (EMF) is a high-speed method that is used to shape a workpiece using pulsed magnetic forces. The deformation rate can be as high as $10^{3}$ to $10^{4} / \mathrm{s}$. EMF is suitable for high conductive materials such as aluminum alloys. The merits of EMF are discussed in more detail in a review article by Psyk et al. [3]. Compared to traditional quasi-static stamping processes, the EMF increases the formability [4-6] of the material and significantly inhibits the springback of the workpiece.

There are two parts in the theoretical analysis of EMF: magnetic pressure calculation and workpiece dynamic deformation analysis. Finite element simulation provides a chance to better understand the multi-physics-coupled processes of EMF. Up to now, there have been two main simulation methods that are typically used to model the EMF process: (1) loose coupling and (2) sequential coupling. Differences between the methods were previously analyzed in the work of Cui et al. [7]. If the magnetic force calculation is not based on the geometrical model of workpiece deformation, the simulation approach is considered to be a coupling method that is too loose. Therefore, for EMF, the sequential coupling method can obtain higher accuracy calculations, because it takes into account the influence of workpiece deformation in the calculation of the magnetic field. For both methods, solid elements have been used to predict the EMF process due to the volume forces generated on the workpiece caused by skin effects. For example, Cui et al. [8] accuracy predicted the large-scale ellipsoid parts deformation process by incremental EMF combined with stretch forming. In another study, Cui et al. [9] used simulations to obtain a uniform tube thickness stress distribution by applying multi-directional magnetic pressure combined with axial and radial magnetic forces on the tube. Yu et al. [10] analyzed the effect of current frequency on radial deflection by electromagnetic tube compression. However, the shell element may obtain more accurate simulation results for metal sheet forming compared to the solid element, especially for springback simulations. Therefore, it needs to develop an electromagnetic-forming simulation method using a shell element.

Magnetic pulses forming make local loading of the workpiece easier, and many researchers have also shown that electromagnetic-assisted stamping (EMAS) can reduce or eliminate springback [11-17]. With EMAS, the sheet is first bent by a punch that moves downwards; then, magnetic pulses are discharged in the bend area by the working coil embedded in the punch. Shang et al. [11] proposed a V-shaped bending method and analyzed the effect of discharge energy on the sheet springback angle using 2024-T3 aluminum alloy. Liu et al. [12] and Sun et al. [13] used the electromagnetically-assisted bending method to reduce the springback of U-shaped parts. In addition, Iriondo et al. [14,15] established an L-shaped parts bending method and evaluated the effect of magnetic forces on the springback reduction of DP600 high-strength steel and 5754 aluminum alloy. Other studies have also used electromagnetic forces to improve upon electromagnetic-forming processes. For instance, Woodward et al. [16] used disposable actuators to control springback. Hu et al. [17] used a uniform pressure coil with a V-shape to perform electromagnetic calibration tests.

To explore the mechanism of the springback reduction during electromagnetic forming, Cui et al. $[18,19]$ found that high-frequency oscillations occur in the sheet bending region, and the tangential stress decreases sharply after the electromagnetic coil is discharged. Based on this mechanism, a reverse bending and springback-control method was proposed by Cui et al. [20], as shown in Figure 1c. Compared to conventional EMAS to reduce springback (in Figure 1a), the new method (in Figure 1c) can greatly extend the operating lifetime of the mold due to without changing the punch structure used in conventional stamping technology. Thus, this approach is adopted for commercial production. 


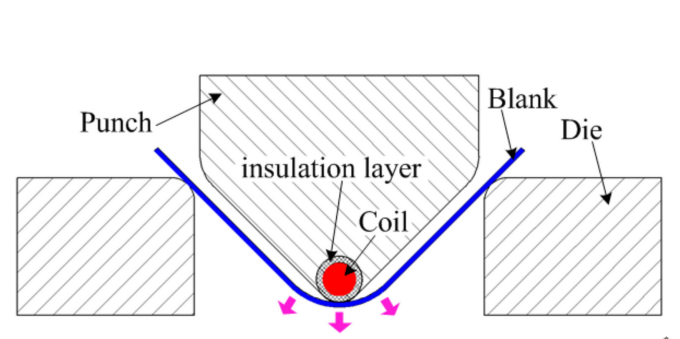

(a)

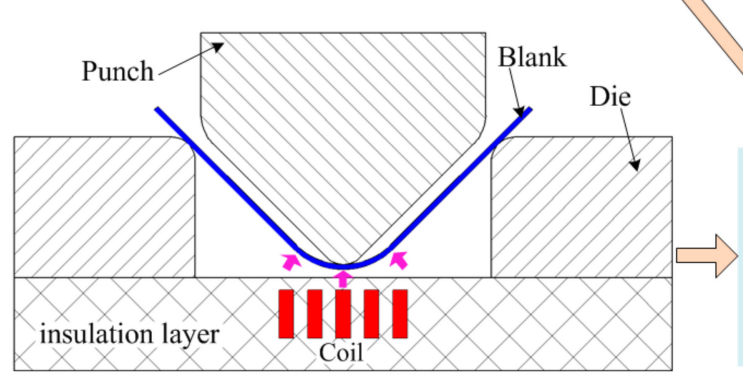

(c)

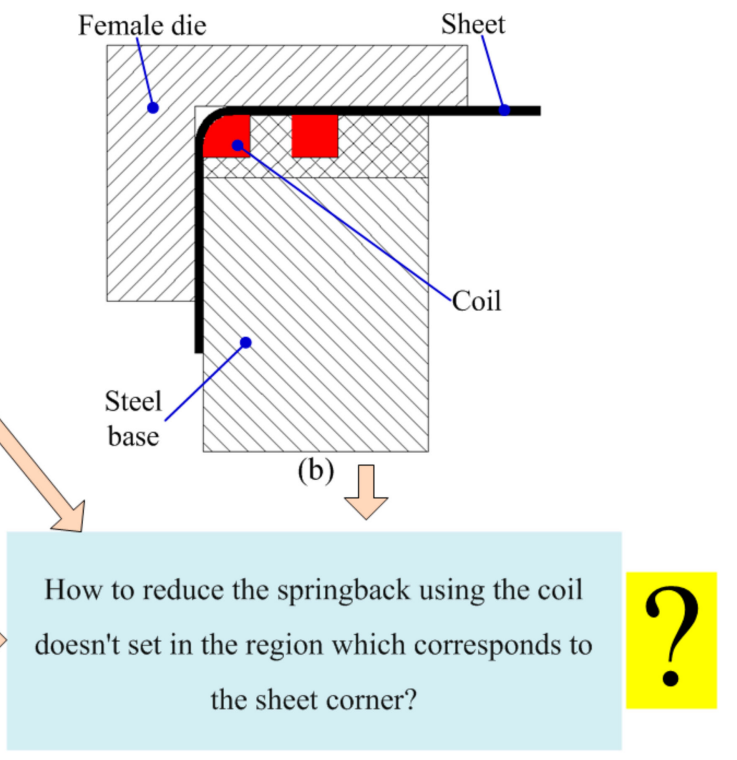

the sheet corner?

Figure 1. Existing springback reduction methods using magnetic pulse forming: (a) V-shaped part using the coil embedded in the punch, (b) L-shaped part, (c) V-shaped part using inverse magnetic force.

Up to now, all of the springback reduction methods using magnetic pulse forming have a common problem, which is that the positions of the working coils are all set in the region that corresponds to the sheet bending region, as shown in Figure 1. Figure 1a shows the most common approach to reduce springback using EMF. To manufacture the punch, the corner region of the punch is hollowed out firstly; then, the copper conductor is embedded into the hollow. Thus, the punch has a low operating lifetime for stamping and EMF processes. The schematic illustration of the L-shaped bending process and magnetic pulse springback calibration, as described in [14], is shown in Figure 1b. First, the steel punch and die bend the sheet metal. Then, the steel die is replaced by a composite die consisting of a steel base, epoxy plate, and coil. Thus, the system needs two sets of concave die structures for the stamping and EMF processes, which reduce the forming efficiency. Moreover, manufacturing the compound die is difficult. Figure 1c shows the newest method to reduce springback by inverse magnetic force proposed by Cui et al. [20]. However, this method is suitable for the free bending of sheet metal. Therefore, it is necessary to design a new springback reduction method that does not require a coil to be placed at the sheet bending region.

In this paper, we designed a new springback calibration method for EMF. The proposed approach does not require magnetic forces to be generated at the sheet corner. Moreover, a new simulation method for modeling the EMF process based on shell elements is proposed and used to predict the accuracy of forming process and springback during the quasi-static stamping.

\section{Method and Material}

\subsection{Forming Method}

The novel method for L-shaped bending and springback calibration is proposed in this paper and presented in Figure 2. During the EMF process, the coil is set at the sheet end. In order to make the material show obvious oscillating behavior during the EMF process, the gap between the blankholder and die is larger than the thickness of the sheet. Thus, there exist two forming methods as follows.

Forming method 1: As shown in Figure 2a,c,d, the sheet is clamped by the blankholder and die during the stamping process. After the quasi-static stamping, the blankholder moves up, and then the coil discharges. 
Forming method 2: As shown in Figure 2b,d, the distance between the blankholder and die is greater than the sheet thickness at the initial state. After the quasi-static stamping, the coil discharges immediately.

According to the description of the forming principle, two methods have the same effect to reduce springback. Due to forming method 2 being easy to realize, this paper analyzes the effect of the distance between the blank holder and die and discharge voltage on springback reduction based on forming method 2.

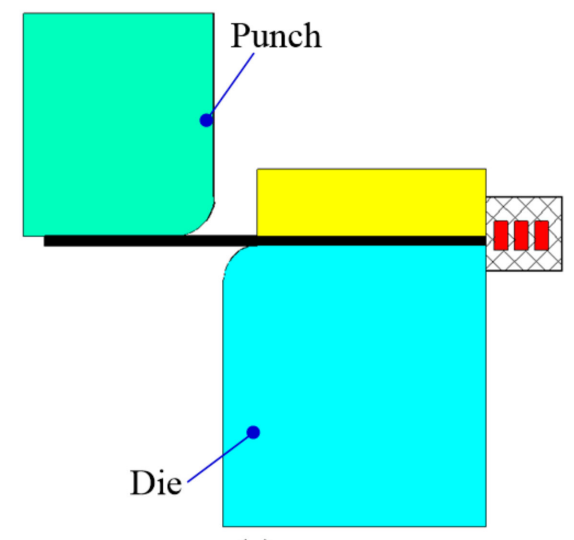

(a)

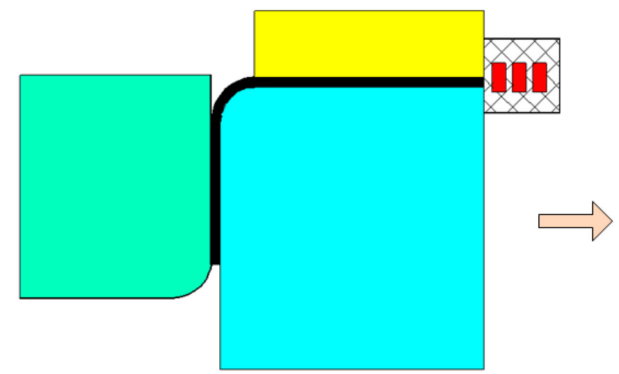

(c)

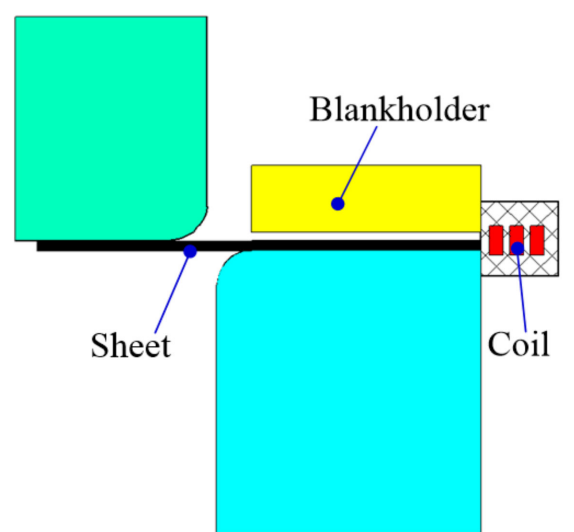

(b)

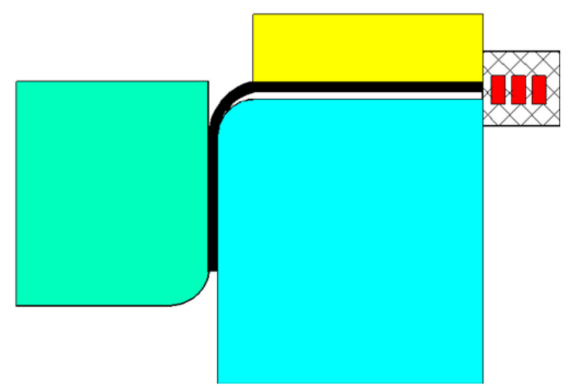

(d)

Figure 2. Schematic diagram of the L-shaped part bending and magnetic pulse springback calibration using (a) the initial state of forming method 1, (b) the initial state of forming method 2, (c) the quasi-static stamping of forming method 1 , and (d) the coil discharge both in forming method 1 and 2.

\subsection{Materials and Geometrical Model}

Figure 3 shows the forming device designed according to the forming principles presented in Figure $2 \mathrm{~b}$. To reduce the complexity of the forming process, the blank holder and coil were arranged as a single structure. Figure 3a shows the combined three-dimensional (3D) structure of the die and blank holder. The blank holder, as illustrated in Figure 3b, was manufactured using an epoxy plate with a step structure at the bottom. The left side of the flat step was used to press the flange area of the sheet metal, and multiple grooves were created on the right side of the step. The $3 \mathrm{~mm} \times 6 \mathrm{~mm}$ copper wire was embedded into the grooves as the discharge coil. The length, width, and thickness of the sheet metal were $90 \mathrm{~mm} \times 40 \mathrm{~mm} \times 1 \mathrm{~mm}$. The main parameters of EMF equipment are as follows: the maximum discharge energy $(200 \mathrm{~kJ})$, rated voltage $(25 \mathrm{kV})$, and capacitance $(640 \mu \mathrm{F})$. To analyze the feasibility of the proposed method, the effect of two process parameters on springback were analyzed: (1) the distance between the blank holder and die, which is defined as h; and (2) the discharge voltage, which is defined as $U$. 


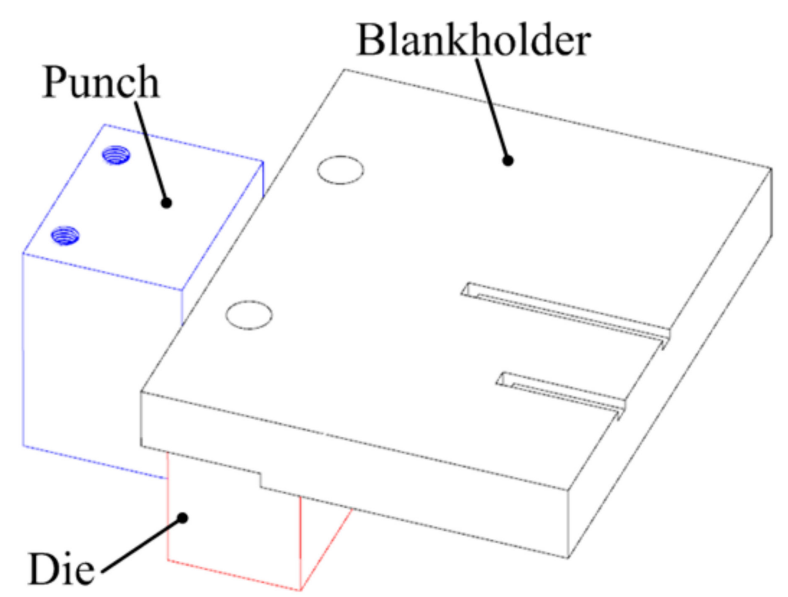

(a)

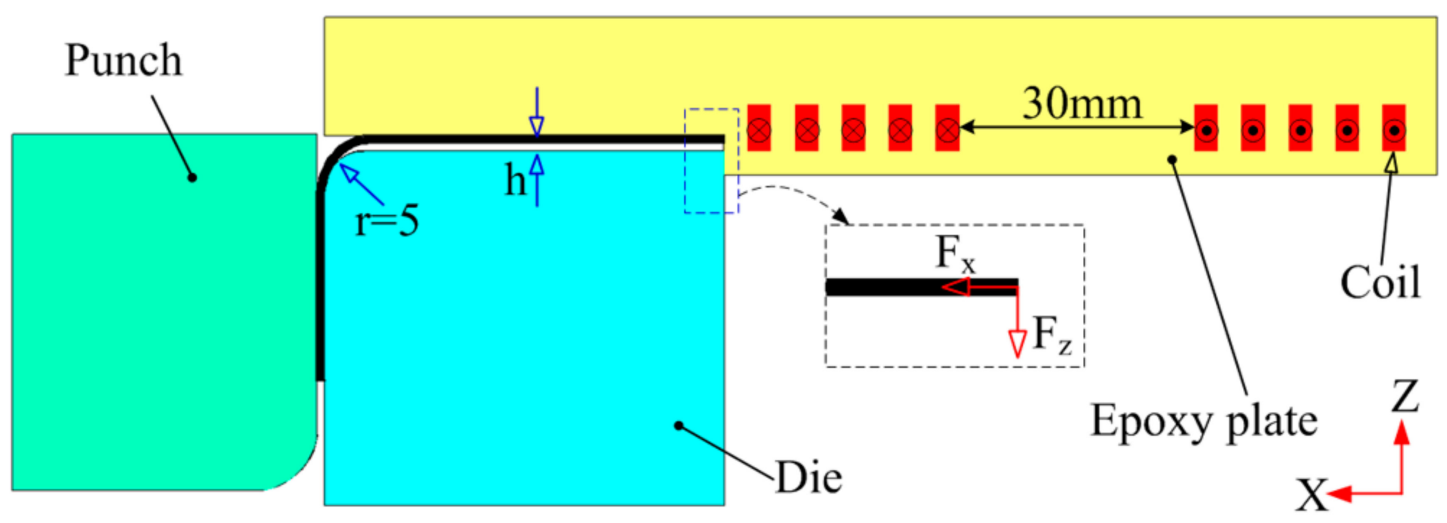

(b)

Figure 3. Forming system: (a) schematic diagram of 3D metal sheet forming device, (b) 2D forming device.

The experiment used the 5052-O aluminum alloy material. The yield strength, Young's modulus, and Poisson's ratio were $105.8 \mathrm{MPa}, 68 \mathrm{GPa}$, and 0.33 , respectively. The stress-strain relationship for the 5052 aluminum alloy can be expressed as [21]:

$$
\sigma_{S}=474.6(\varepsilon+0.01866)^{0.377}
$$

where $\sigma_{\mathrm{S}}$ is the quasi-static stress and $\varepsilon$ is the plastic strain.

During the electromagnetic-forming (EMF) process, the deformation time of sheet metal is very short, and the temperature of sheet metal hardly increases. For example, Cui et al. [22] showed that the tube had a temperature rise of about $5{ }^{\circ} \mathrm{C}$ after discharge based on a numerical simulation. Cui et al. [23] showed that the temperature on the sheet before and after discharge was changed a very small amount $\left(0.1^{\circ} \mathrm{C}\right)$ by the experiment. Moreover, we did not find any heating of the sheet in this experiment. Thus, the effect of temperature on the material model can be neglected during EMF. Equation (1) describes the quasi-static stress-strain relationship of the sheet metal. In order to describe the effect of high strain rate on the forming process, the Cowper-Symonds constitutive model is used, as shown in Equation (2). The data in Equations (1) and (2) are quoted from the literature of Cui et al. [21].

$$
\sigma=\sigma_{s}\left(1+\left(\frac{\dot{\varepsilon}}{P}\right)^{m}\right)
$$

where $\sigma$ is the dynamic flow stress; $\sigma_{\mathrm{S}}$ is the quasi-static stress; $\dot{\varepsilon}$ is the strain rate; and P and $\mathrm{m}$ are the specific properties of the aluminum alloy, $\mathrm{P}=6500 \mathrm{~s}^{-1}$ and $\mathrm{m}=0.25$. 


\section{Finite Element Modeling}

\subsection{Quasi-Static Stamping}

Figure 4 shows the finite element model for quasi-static stamping. For the simulation, the punch, die, and blankholder were all set as a rigid body structure. During the stamping, the blankholder and die were in a fixed position, while the punch moves down $50 \mathrm{~mm}$ to bend the sheet. To compare the use of a solid element or shell element on the forming and springback simulation, the metal sheet was modeled using both. The solid element type was C3D8, and the shell element was S4. For the solid element type of the sheet, the number of elements in the thickness is set to 4 . For both elements, the simulation was performed assuming a gap of $2 \mathrm{~mm}$ between the blank holder and die. The results are shown in Figure $4 b, c$. The upper surface of the sheet makes adequate contact with the blank holder after quasi-static bending, as shown in Figure $4 \mathrm{~b}$.

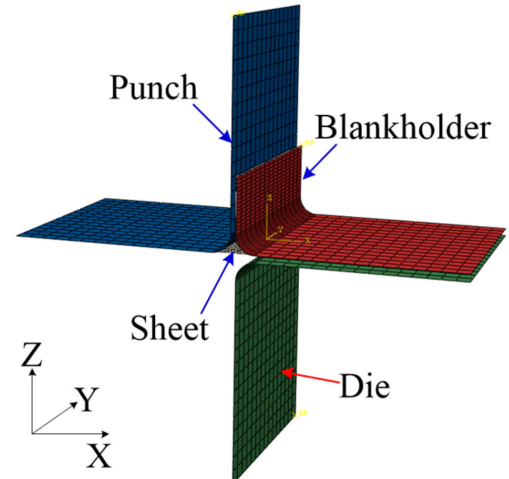

(a)

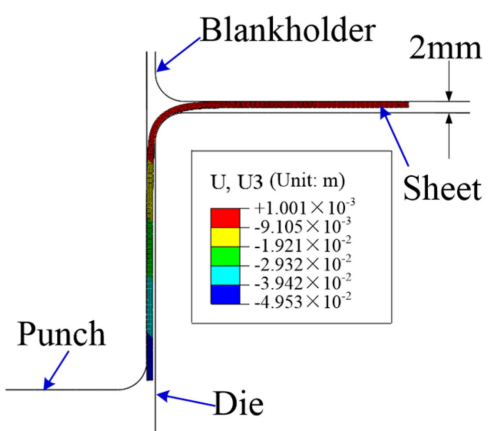

(b)

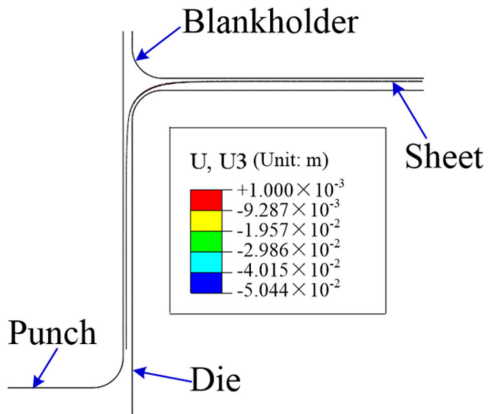

(c)

Figure 4. (a) 3D model of quasi-static stamping, (b) solid element, (c) shell element.

Using the parameters obtained from the stamping experiment, the springback of the sheet metal was simulated using both the solid and shell elements, as shown in Figure 5. The deformation results calculated by Abaqus/Explicit were imported into Abaqus/Implicit to calculate the springback of the metal sheet. Assuming that all parameters remain the same, the springback angle obtained by the experiment was $10^{\circ}$ after the metal sheet was bent $90^{\circ}$. The springback angles using the solid element and shell element were $8.8^{\circ}$ and $9.9^{\circ}$, respectively. Thus, the springback angle obtained by the shell element has a high accuracy predicted compared to the experimental result. Inconsistencies between the predictions were mainly due to the differences between the elements in the finite element method. Thus, for calculating the springback after sheet forming, the shell element produces better results.

\subsection{Electromagnetic Forming Process}

If a metal workpiece is placed in an alternating magnetic field, it will produce an electromagnetic force within a certain range of workpiece thicknesses according to the law of electromagnetic induction. This is referred to as the skin effect. Therefore, solid elements must be used in electromagnetic field simulations. Based on the simulation results presented in Figure $4 \mathrm{~b}$, our laboratory has established a three-dimensional electromagnetic field model, as shown in Figure 6a. The entire electromagnetic field model includes five parts: discharge coil, bent sheet metal, punch, near-field air, and far-field air. The coil, sheet, and punch are meshed with SOLID 97 elements and an eight-node hexahedral element. The air that surrounds the sheet and coil is meshed with pyramidal and tetrahedral elements to propagate the magnetic field generated by the coil. The far-field air region is meshed with INFIN110 elements and an eight-node hexahedral element. During the EMF, the current density is loaded into the coil, and the far air flag is load on the exterior surface of the whole finite element model. 


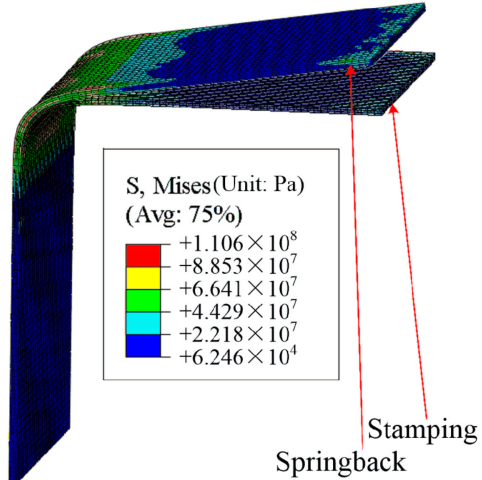

(a)

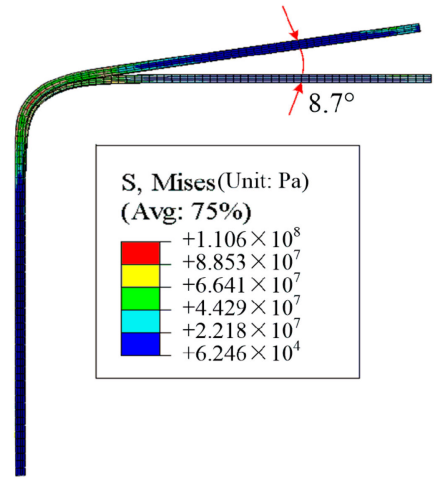

(d)

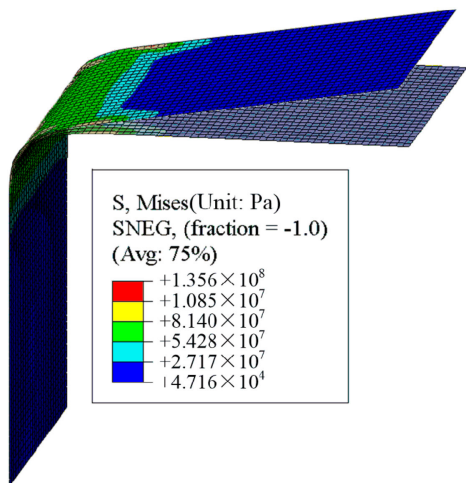

(b)

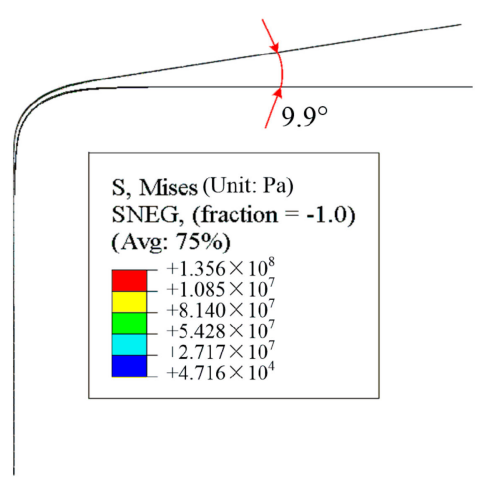

(e)

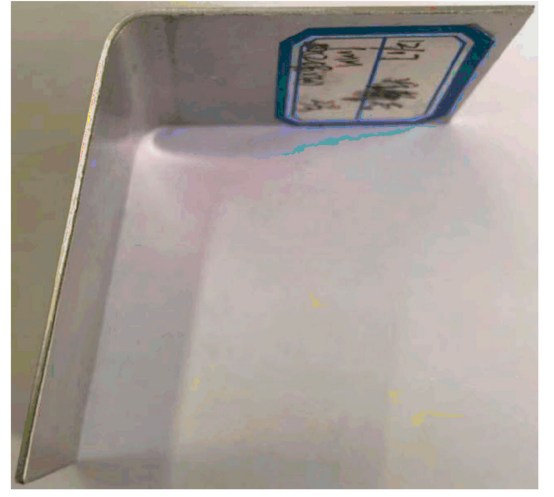

(c)

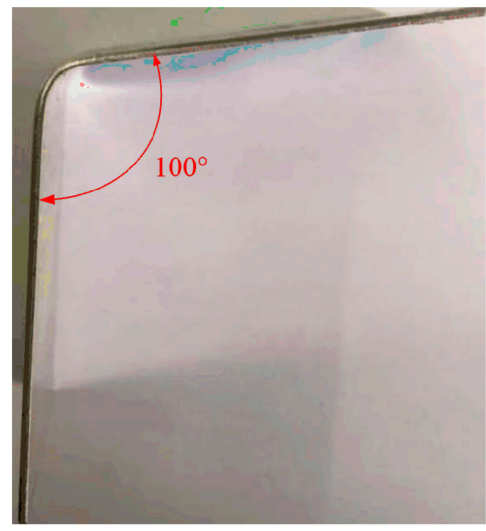

(f)

Figure 5. Simulation and experimental results for springback angle: three-dimensional view (a-c) and two-dimensional view (d-f) using the solid element $(\mathbf{a}, \mathbf{d})$, shell element $(\mathbf{b}, \mathbf{e})$, and by experiment $(\mathbf{c}, \mathbf{f})$.

The current flowing through the coil under a discharge voltage of $5000 \mathrm{~V}$ is shown in Figure $6 \mathrm{~b}$. Multiple discharge pulses will increase the coil temperature and greatly reduce the service life of the EMF equipment. Thus, we retain the first current wave and filter out the other discharge pulses waveforms. The discharge circuit is same as the one cited in the literature [24]. During the EM simulation, when the coil was loaded with current, it was assumed that the current flows counterclockwise around the coil at $\mathrm{t}=10 \mu \mathrm{s}$, as shown in Figure 6c. The induced current generated on the sheet and punch is shown in Figure 6d,e. A complete current loop was obtained in the sheet, as well as between the sheet and the punch. A large induction current was generated at the end of the metal sheet on the side facing the coil. Figure $6 \mathrm{f}$ shows the magnetic flux density on the sheet. The axial magnetic flux will produce a magnetic pressure along the X-axis, as shown in Equation (3). For the node 3067, the magnetic field intensity along the Z-axis is $-0.18 \mathrm{~T}$. Thus, the magnetic along the $\mathrm{X}$-axis is $0.13 \mathrm{MPa}$ at $10 \mu \mathrm{s}$, which is loaded at the sheet end.

$$
P_{x}=\frac{B_{z}^{2}}{2 \mu_{0} \mu_{1}}
$$

where $P_{x}$ is the magnetic pressure along the $X$-direction, $B_{z}$ is the magnetic field intensity along the $\mathrm{Z}$-direction, $\mu_{1}$ is the relative magnetic permeability of the aluminum alloy, and $\mu_{0}$ is the magnetic permeability in vacuum. In this case, $\mu_{1}$ and $\mu_{0}$ were set to 1 and $4 \pi \times 10^{-7} \mathrm{~N} / \mathrm{A}^{2}, 1 \mathrm{~T}=1 \mathrm{~N} /\left(\mathrm{A}^{*} \mathrm{~m}\right)$. 


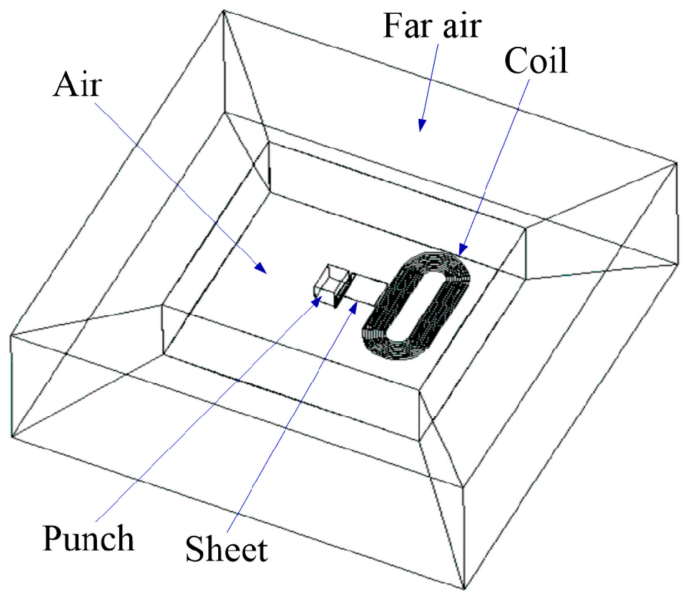

(a)

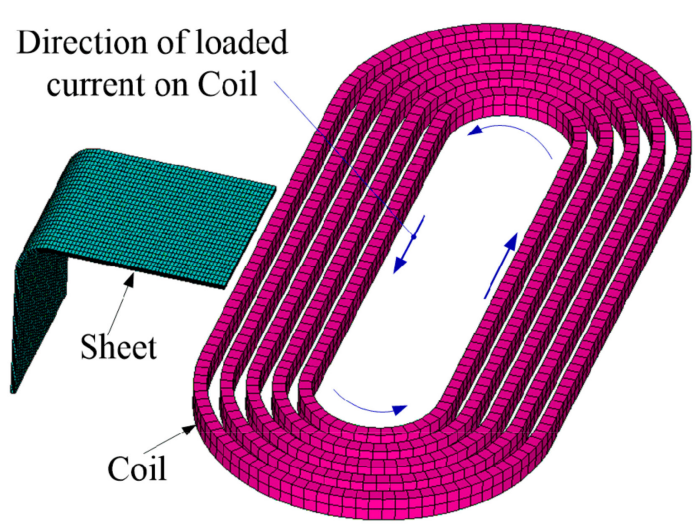

(c)

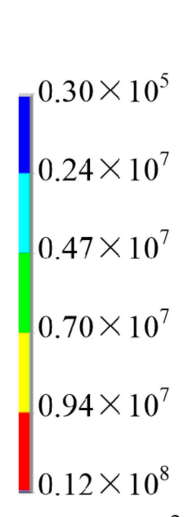

Unit: $\mathrm{A} / \mathrm{m}^{2}$

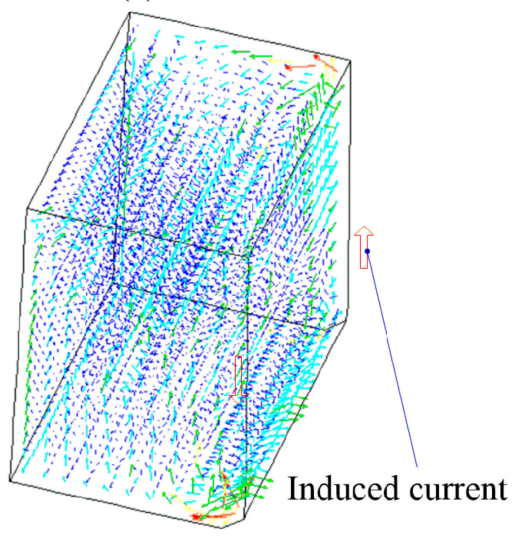

(e)

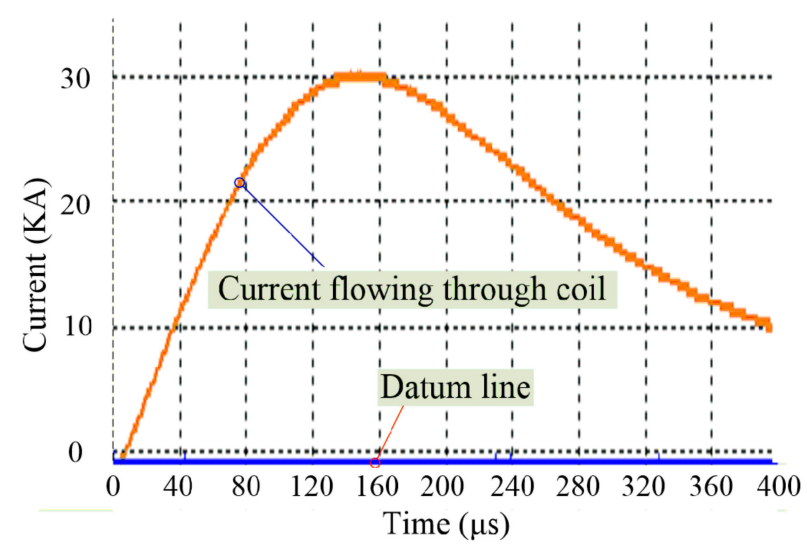

(b)

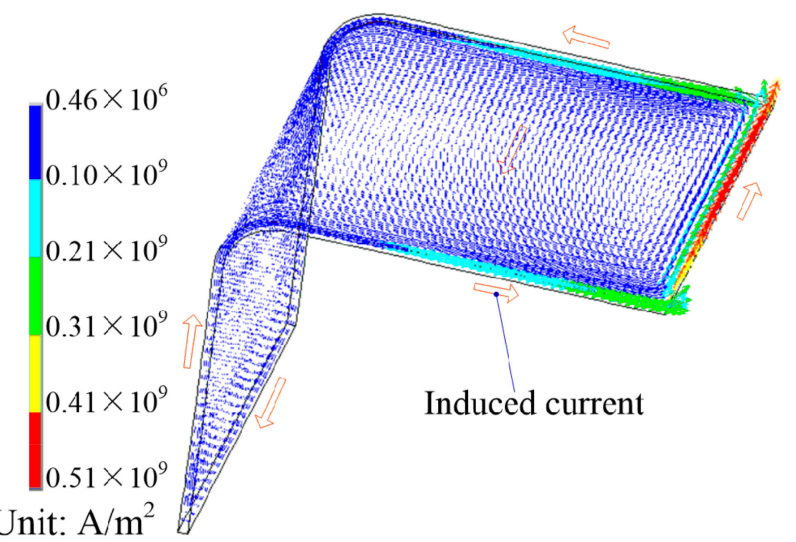

(d)

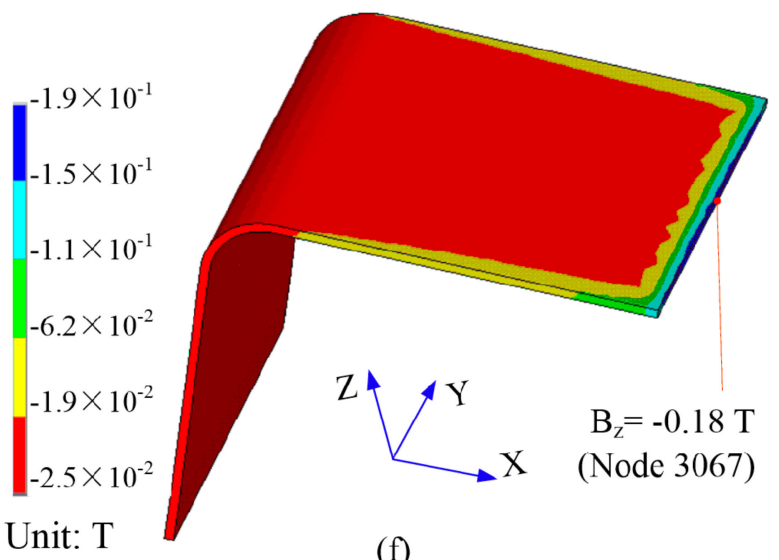

(f)

Figure 6. Electromagnetic field analysis: (a) 3D model, (b) measured current, (c) meshes of sheet and coil, (d) induced current on sheet, (e) induced current on punch, and (f) magnetic flux density on sheet.

According to Figures 5 and 6, the solid element should be used for magnetic field force calculation during the electromagnetic field simulation. However, large errors occur when calculating the springback angle using the solid element. Therefore, the shell element should be used to more accurately predict springback. The electromagnetic force previously calculated using the solid element electromagnetic field model must be transformed into the equivalent electromagnetic force for the shell element. The simulation process is illustrated in Figure 7. First, the ANSYS/EMAG program was used for magnetic force calculation for each node in the solid element. Then, the magnetic force were imported into the ABAQUS/EXPLICIT program to analyze the sheet deformation, and the updated 
deformed solid mesh was imported back into the ANSYS EMAG program to calculate the next magnetic force. The magnetic field/structure coupling analysis was realized using the conditions obtained for the solid element. As a result of the shape changes of the metal sheet, the magnetic field was taken into account during each step of the analysis. This ensured the accuracy of the magnetic field force calculation using the solid element.

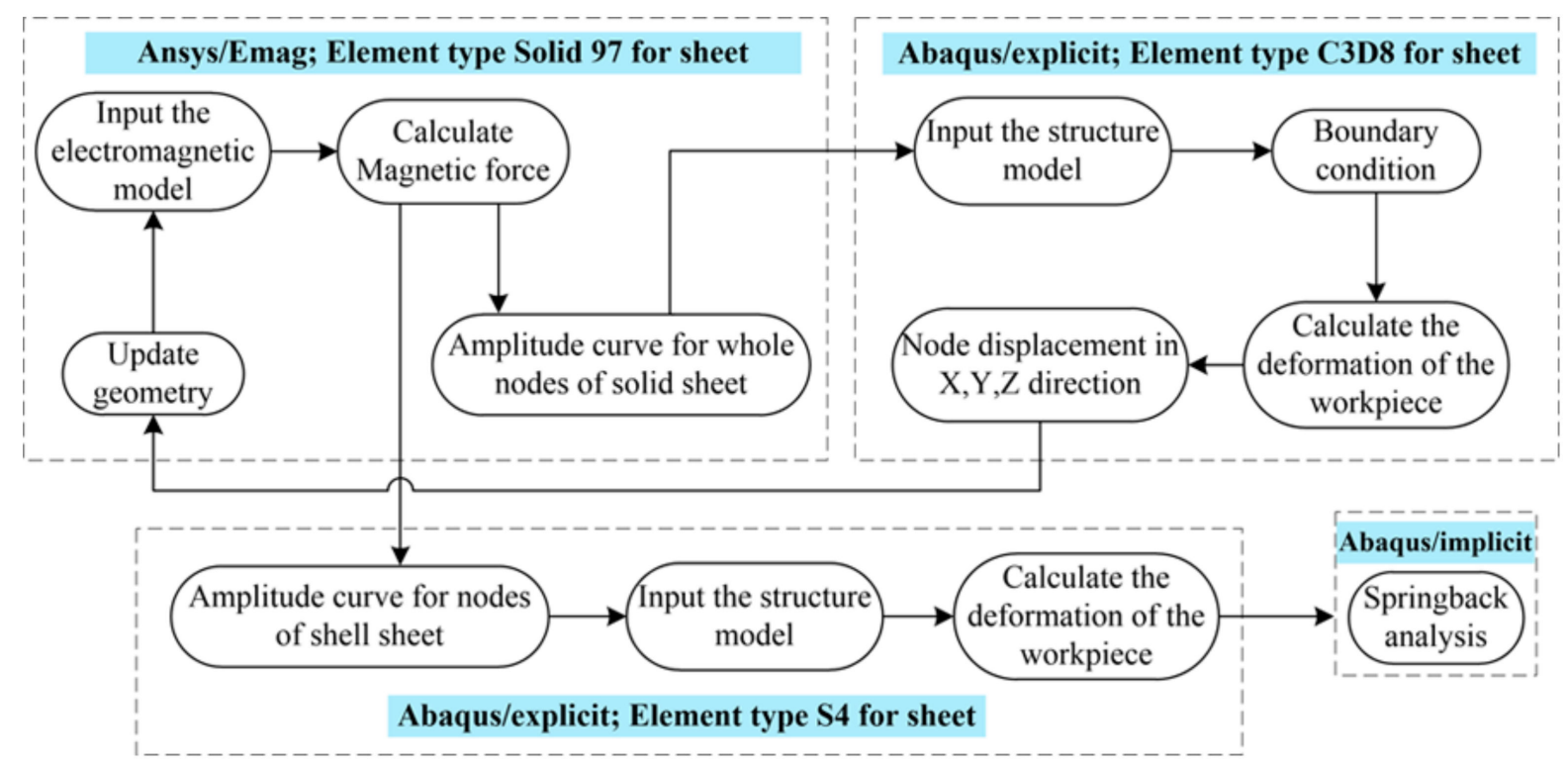

Figure 7. Flowchart of electromagnetic-forming process and springback simulation using either a solid or shell element.

The magnetic force at each node of the solid element was translated into the magnetic force at each node of the shell element. Then, the magnetic force data at each node of the shell element was imported into Abaqus/Explicit to model the magnetic pulse forming process. Finally, the deformation results were imported into Abaqus/Implicit, and the springback angle was calculated.

To simulate the forming process shown in Figure 7, a relationship between the solid element nodes and shell element nodes was defined. Using the concept presented in Figure 8 and assuming that Figure 8a represents a solid element after bending, five nodes exist in the sheet thickness direction. The mid-layer shown in Figure 8a was extracted and positioned within the shell element plane, as shown in Figure $8 b$. This ensured that five nodes on the solid element corresponded to one node on the shell element. Taking the end node of the sheet metal as an example, five nodes along the thickness direction were defined: $A, B, C, D$, and $E$. The electromagnetic forces were first obtained along the $X, Y$, and $\mathrm{Z}$ directions of nodes $\mathrm{A}, \mathrm{B}, \mathrm{C}, \mathrm{D}$, and $\mathrm{E}$. Then, the five nodes of the solid element were transformed into a single node $F$ of the shell element. The electromagnetic force expressions for node $F$ in the $X, Y$, and $\mathrm{Z}$ directions are as follows:

$$
\begin{gathered}
F_{x(F)}=F_{x(A)}+F_{x(B)}+F_{x(C)}+F_{x(D)}+F_{x(E)} \\
F_{y(F)}=F_{y(A)}+F_{y(B)}+F_{y(C)}+F_{y(D)}+F_{y(E)} \\
F_{z(F)}=F_{z(A)}+F_{z(B)}+F_{z(C)}+F_{z(D)}+F_{z(E)}
\end{gathered}
$$

To facilitate our subsequent analysis, a node at the sheet end (Node 3067), a node at the sheet middle (Node 6985), and the path were chosen, as shown in Figure 8b. 


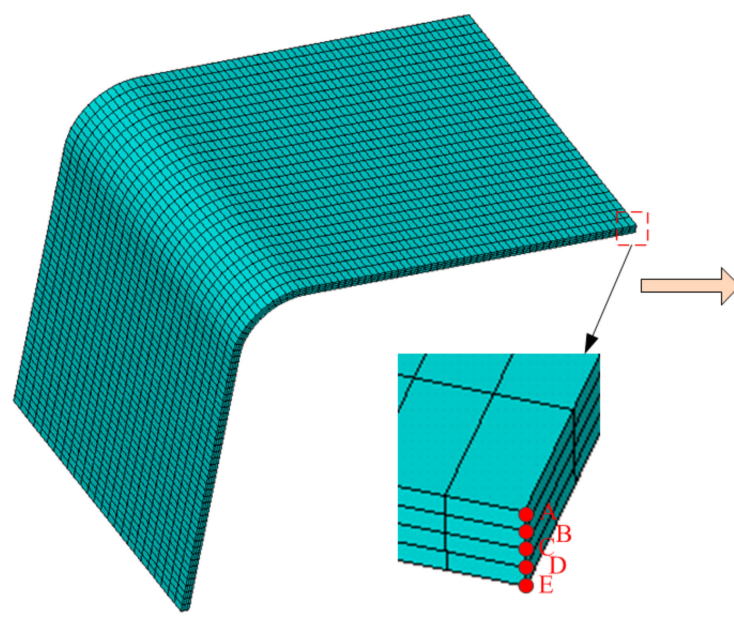

(a)

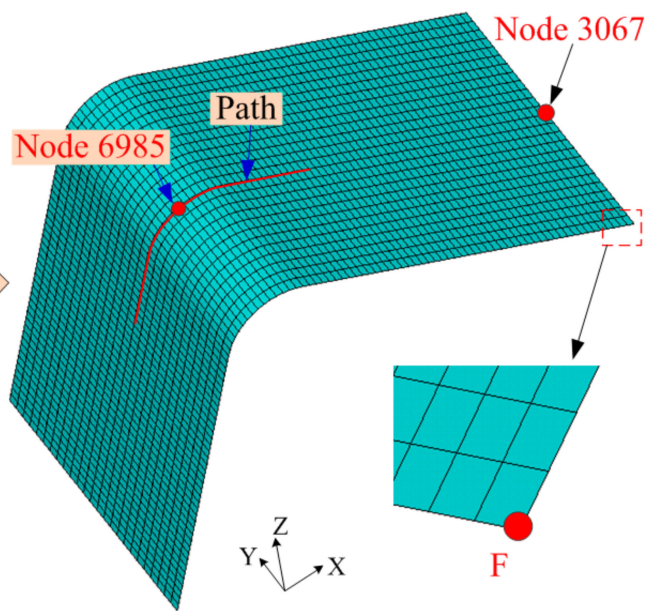

(b)

Figure 8. Magnetic force conversion from (a) solid element to (b) shell element.

\section{Effect Factors on Springback Reduction}

\subsection{Distance between the Blank Holder and Die}

The inflow and magnetic force at node 3067 when $\mathrm{U}=5 \mathrm{kV}$ are shown in Figure 9 for various distances between the blankholder and die (h). A smaller distance between the blankholder and die causes the smaller value of sheet end inflow and the larger the magnetic force (Abs) at node 3067.

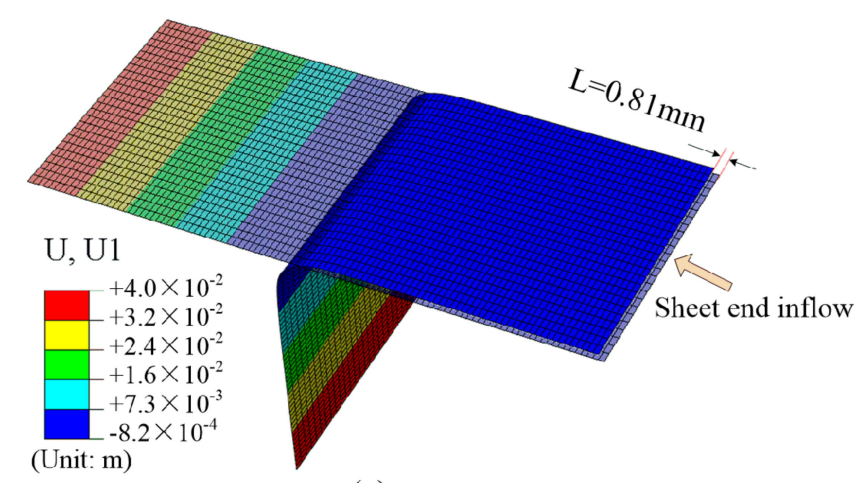

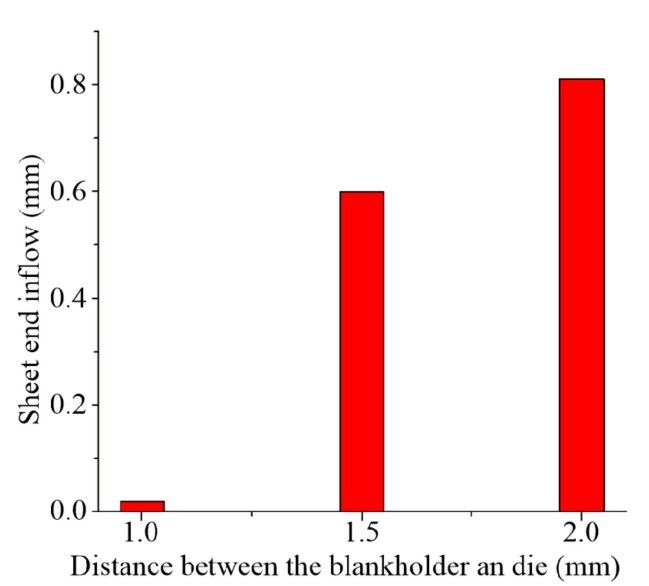

(b)

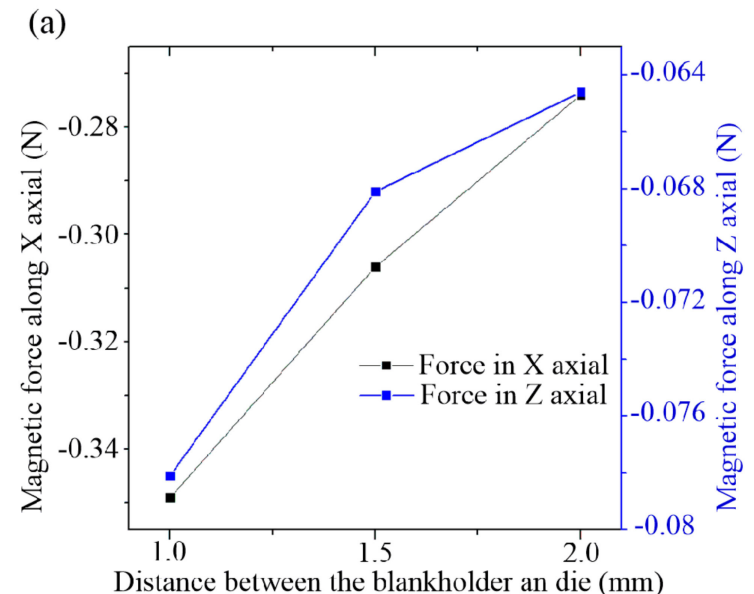

(c)

Figure 9. Effect of distance between the blank holder and die on (a) 3D inflow under h is set to $2 \mathrm{~mm}$, (b) inflow at node 3067, (c) magnetic force at node 3067. 
Figure 10 shows the displacement along the $X$ and Z-axis at node 3067 after the coil discharges and $\mathrm{U}=5 \mathrm{kV}$. If the $\mathrm{h}$ is set to $1 \mathrm{~mm}$, the sheet end does not move along the Z-axis, and only very small displacements occur at node 3067 along the X-axis. If the $\mathrm{h}$ is set to $1.5 \mathrm{~mm}$ or $2 \mathrm{~mm}$ : (1) Displacement along the $X$-axis follows the shape of a parabolic curve. From 0 to $1000 \mu$ s, node 3067 first moves along the negative $X$-axis and then along the $X$-axis. However, differences in the maximum displacement along the $X$-axis are small if the $h$ is set to $1.5 \mathrm{~mm}$ or $2 \mathrm{~mm}$; (2) the sheet end moves first along the negative $Z$-axis, it comes into contact with the upper surface of the die, and then it moves along the Z-axis again. After $600 \mu \mathrm{s}$, the sheet end moves along the negative Z-axis again. From the above analysis, it can be concluded that the sheet end has obvious shake if the distance between the blankholder and die is larger than the sheet thickness. A larger distance between the blankholder and die results in a greater displacement of the sheet end along the Z-axis.

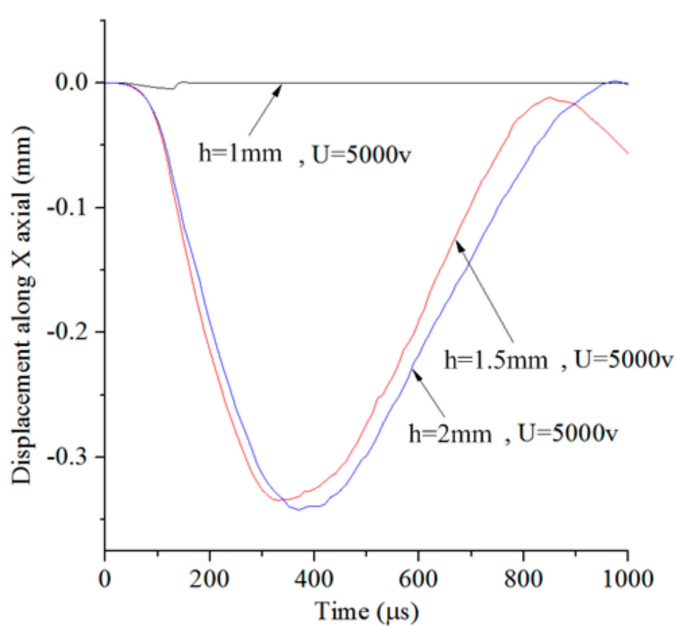

(a)

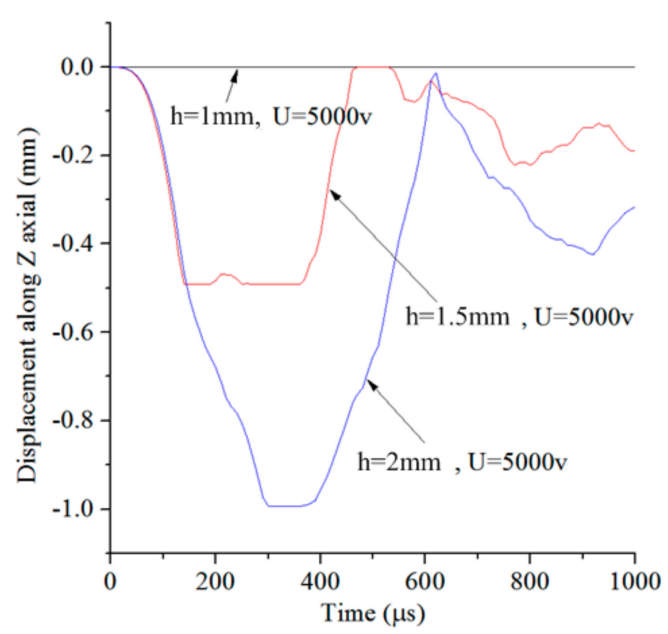

(b)

Figure 10. Displacement at node 3067 along (a) the X-axis and (b) Z-axis.

Figure 11 shows deformation profiles and springback angles after quasi-static stamping and coil discharge for different distances $(\mathrm{h})$ between the blankholder and die. Two observations can be made: (1) A smaller h results in a smaller bending radius after stamping, as shown in Figure 11a, and it leads to a smaller springback angle after quasi-static stamping; (2) A larger $\mathrm{h}$ results in greater differences between the springback angle produced by the coil discharge and quasi-static stamping. If $\mathrm{h}$ is $1 \mathrm{~mm}$, there is almost no displacement along the $X$ and Z-axis at node 3067, which leads to almost no inhibition of springback after the coil discharges. If $\mathrm{h}$ is $1.5 \mathrm{~mm}$ or $2 \mathrm{~mm}$, the coil discharge clearly has much greater inhibitory effects on the springback compared to quasi-static stamping. This suggests that the springback reduction after coil discharge is related to the sheet shake.

\subsection{Discharge Voltage}

The deformation process of the sheet metal when $\mathrm{h}=2 \mathrm{~mm}$ under a $7 \mathrm{kV}$ discharge voltage is shown in Figure 12. From 0 to $200 \mu$ s, the sheet end moves toward the die and gradually makes contact with the die. This results in the bending deformation of the flange of the metal sheet. From 200 to $600 \mu \mathrm{s}$, the sheet end gradually moves toward the blank holder, resulting in some reverse bending of the sheet metal. At $600 \mu \mathrm{s}$, the flange of the metal sheet straightens again. From 600 to $1000 \mu \mathrm{s}$, the sheet end moves toward the die again, and a small bending deformation occurs at $1000 \mu$ s. 


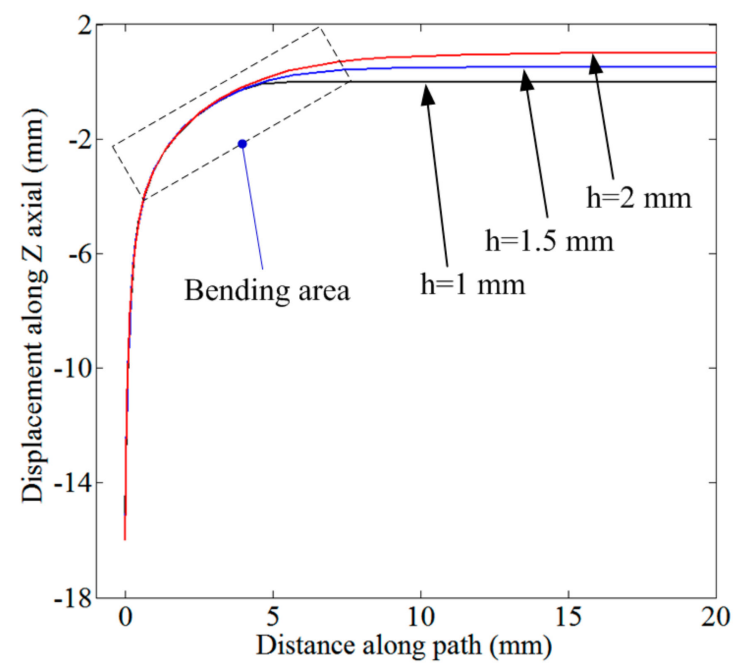

(a)

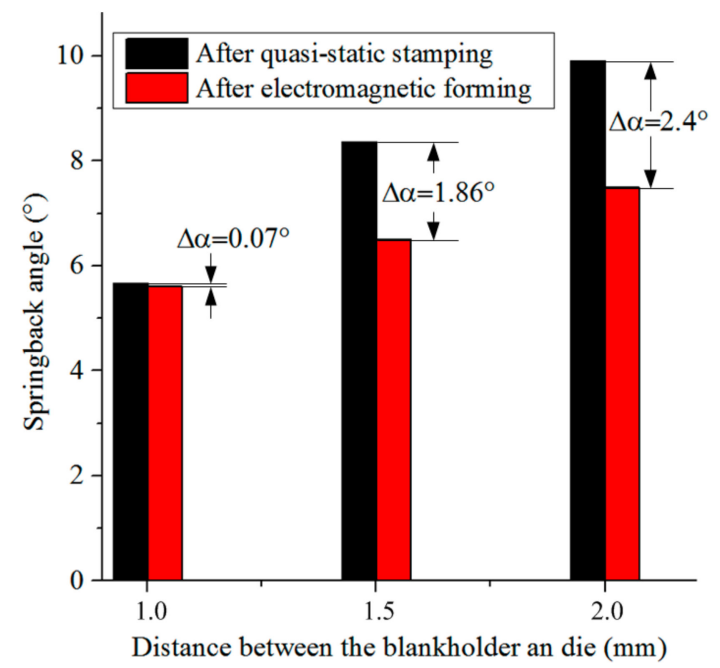

(b)

Figure 11. Deformation and springback reduction based on (a) sheet profiles after quasi-static stamping and (b) springback angle after coil discharge versus quasi-static stamping.

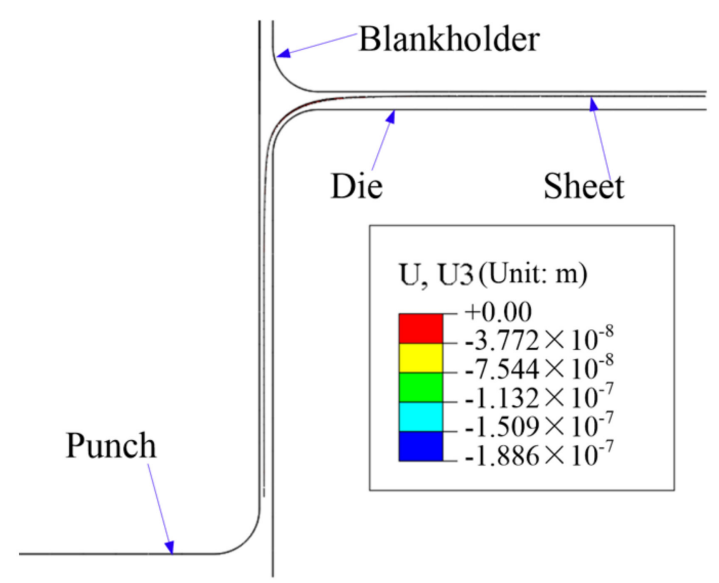

(a)

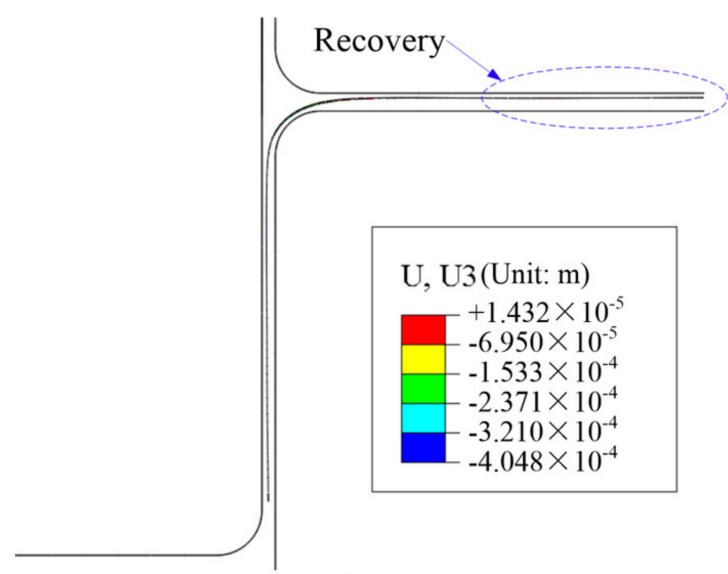

(c)

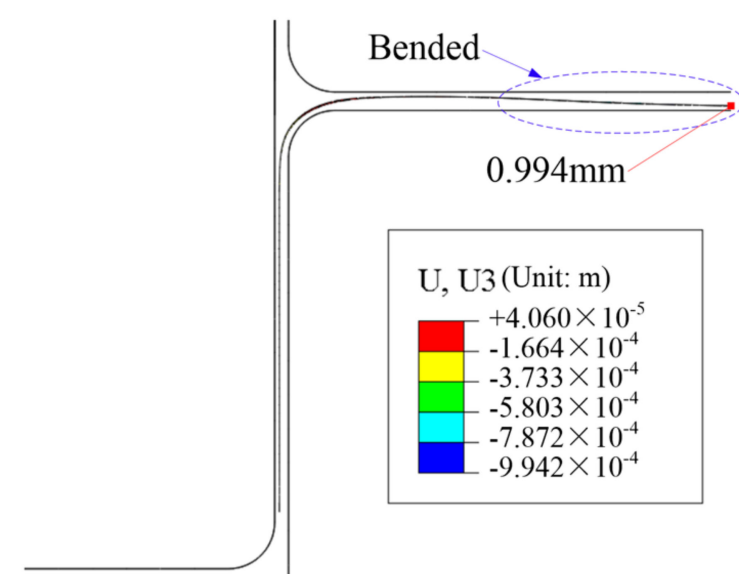

(b)

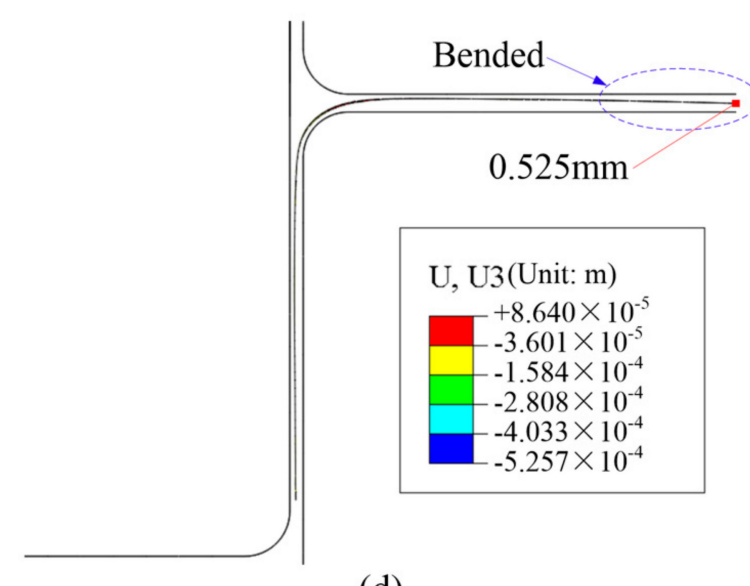

(d)

Figure 12. Deformation profiles after a 7-kV discharge at (a) $0 \mu \mathrm{s}$, (b) $200 \mu \mathrm{s}$, (c) $600 \mu \mathrm{s}$, and (d) $1000 \mu \mathrm{s}$.

Figure 13 shows the displacement along the $X$ and Z-axis at nodes 3067 and 6985 with various discharge voltages. The results shown the following. (1) Node 3067 first moves along the negative Z-axis 
and continues along the $\mathrm{X}$-axis, and as the discharge voltage increases, the maximum displacement along the $X$-axis at node 3067 increases. (2) The maximum displacement along the Z-axis at node 3067 is always the same (up to $1 \mathrm{~mm}$ ) regardless of the discharge voltage. This means that the sheet end will contact the die at different voltages. (3) When the discharge voltage increases, the maximum displacement along the $X$ and Z-axis at nodes 6985 both increase. This shows that the larger the discharge voltage, the more sharply the sheet shakes.

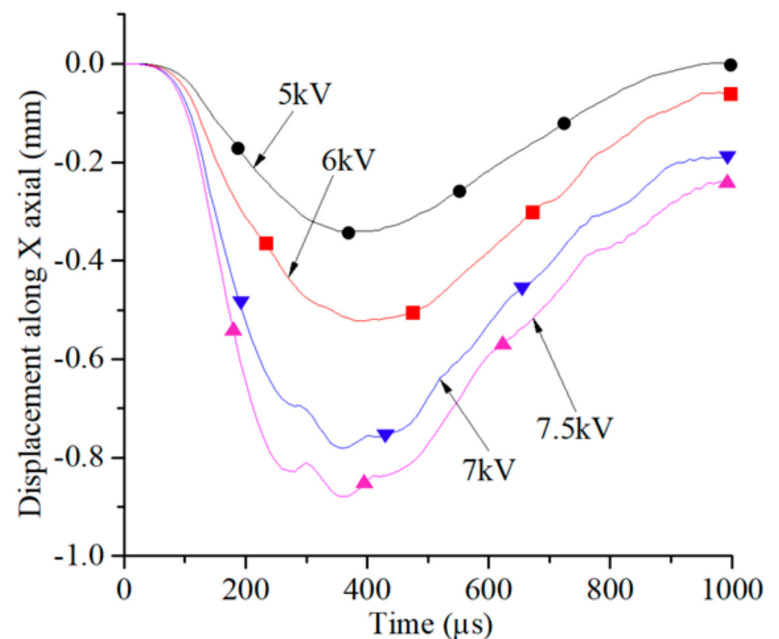

(a)

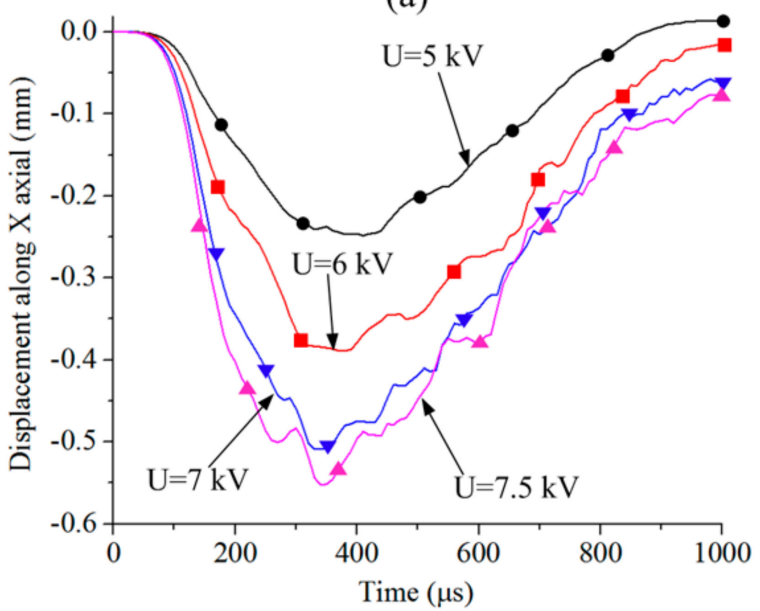

(c)

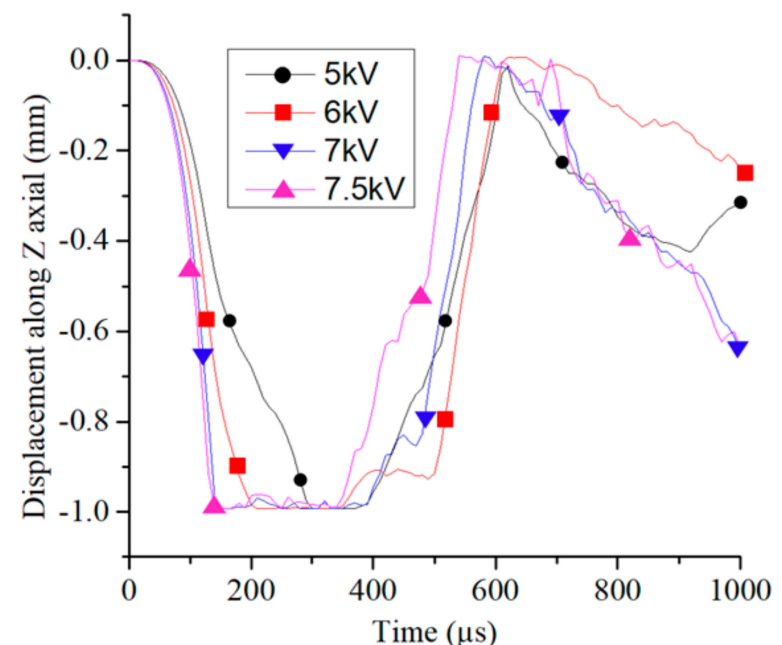

(b)

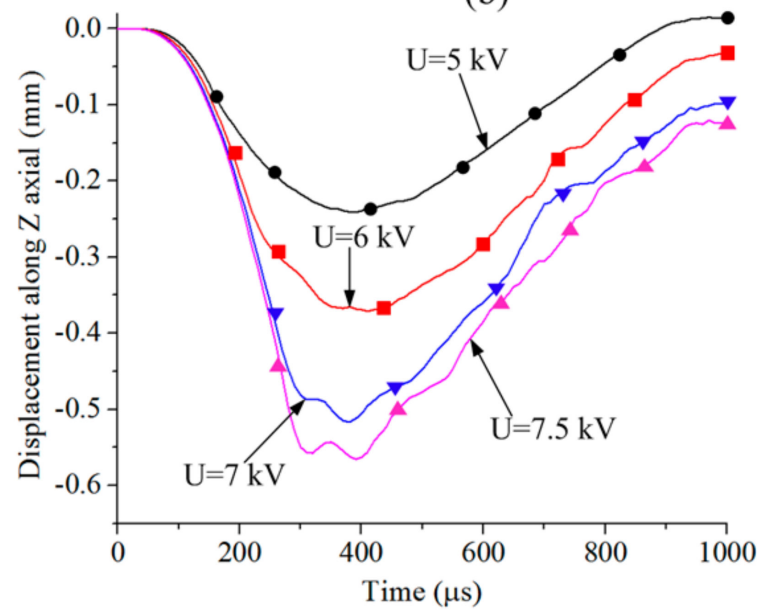

(d)

Figure 13. Displacement vs. time along (a) the X-axis at node 3067, (b) the Z-axis at node 3067, (c) the $\mathrm{X}$-axis at node 6985 , and (d) the Z-axis at node 6985.

To clearly describe the changes in principal stress over time on the metal sheet after the coil discharges, node 6985 (shown in Figure 8) was extracted. The first and second principal stresses at node 6985 show obvious signs of shaking after coil discharge, as illustrated in Figure 14. However, regardless of whether the stress oscillates, the first and second principal stresses both decrease at $1000 \mu \mathrm{s}$. A larger discharge voltage results in increased stress oscillation amplitudes and a smaller maximum tangential stress at $1000 \mu \mathrm{s}$. 


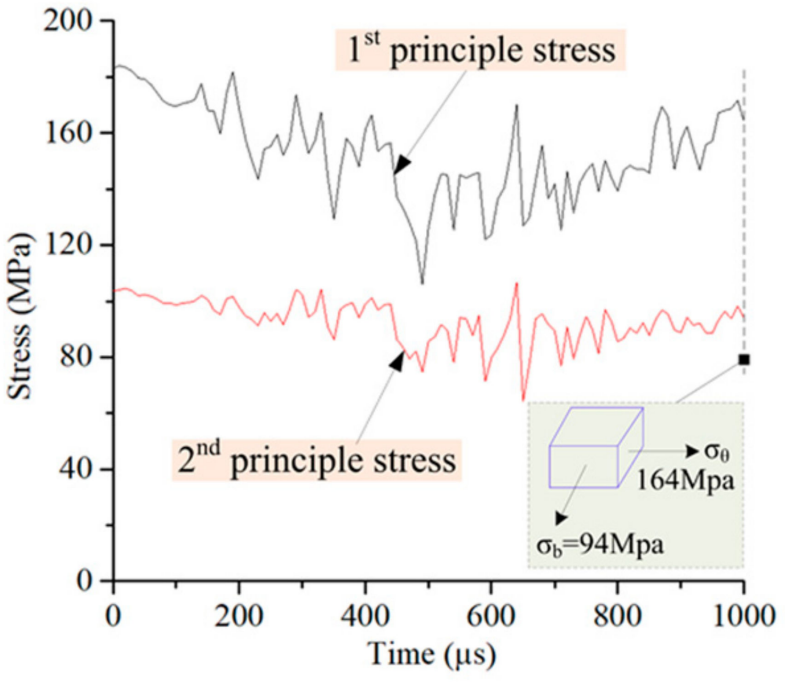

(a)

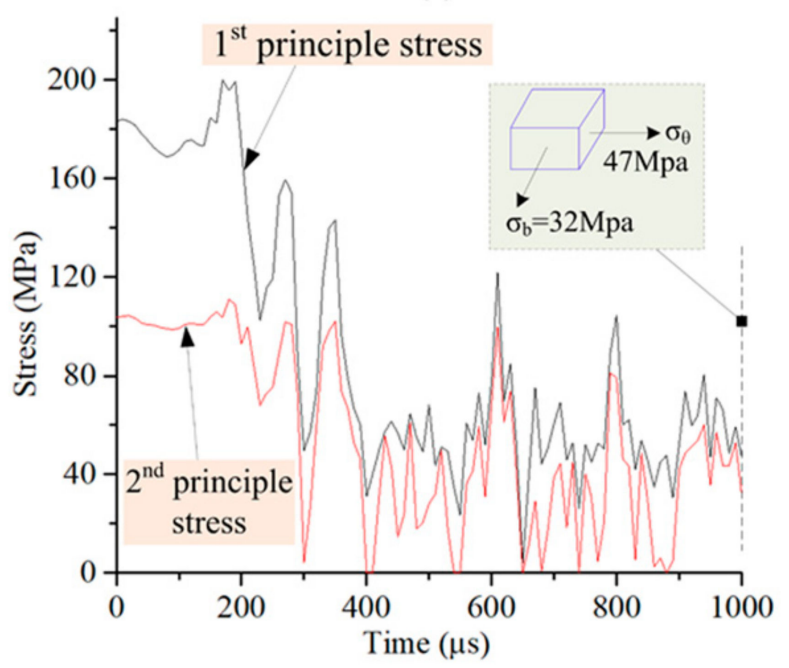

(c)

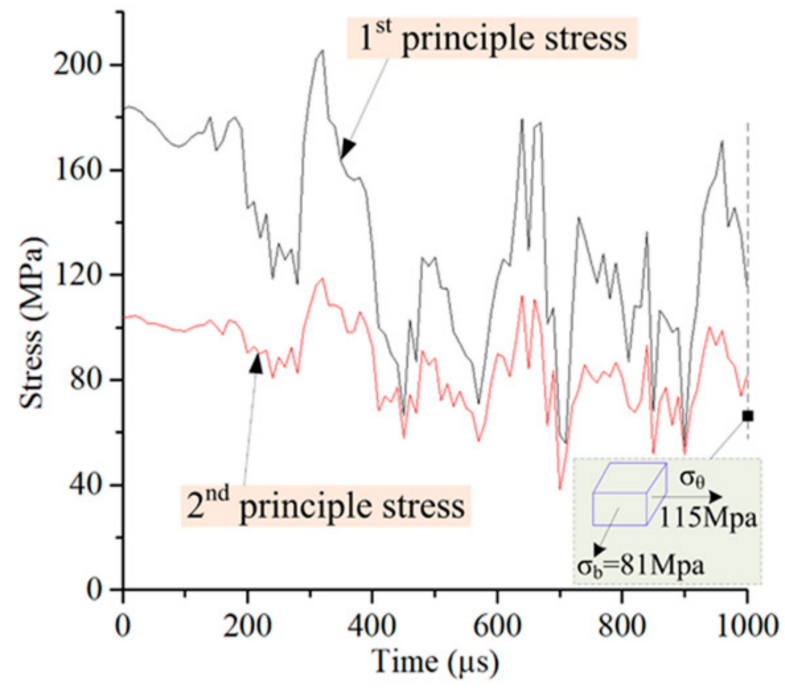

(b)

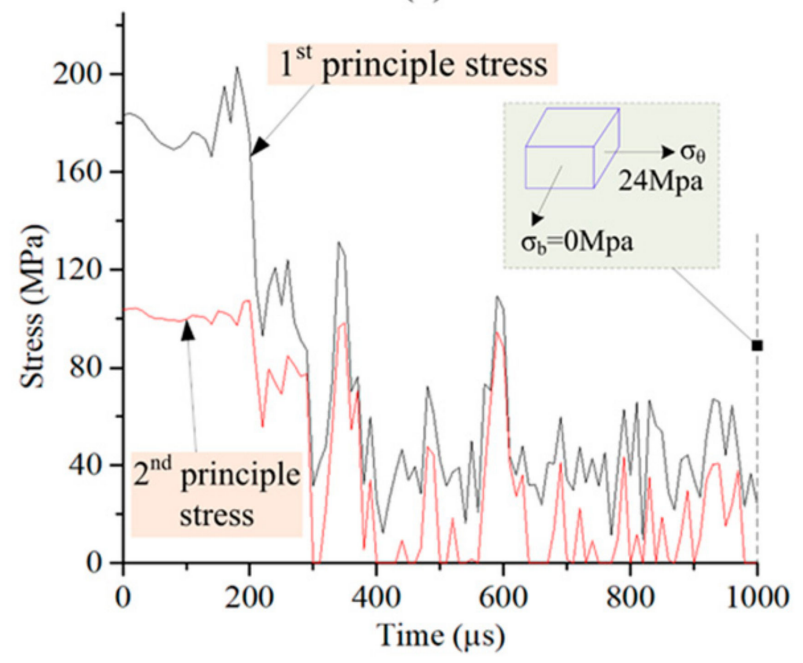

(d)

Figure 14. Principal stress vs. time after coil discharge for a discharge voltage of (a) $5 \mathrm{kV}$, (b) $6 \mathrm{kV}$, (c) $7 \mathrm{kV}$, and (d) $7.5 \mathrm{kV}$.

The distribution of tangential stress in the outer layer of metal sheet at different discharge voltages is shown in Figure 15. Under quasi-static stamping, the tangential tensile stress occurs on the outer layer. The maximum tensile stress reaches $214 \mathrm{MPa}$, which occurs at the bending angle of the sheet metal. Tangential stress is uniformly distributed on the sheet outer layer. After the coil discharges, the tangential stress distributes on the metal sheet and exhibits the following characteristics. (1) A larger discharge voltage results in a more uneven distribution of stress on the outer layer of the sheet metal. (2) A larger discharge voltage leads to a smaller maximum tangential tensile stress on the sheet. (3) As the discharge voltage increases, the maximum tangential tensile stress is no longer concentrated in the bending angle but rather along the straight edge area of the metal sheet. 


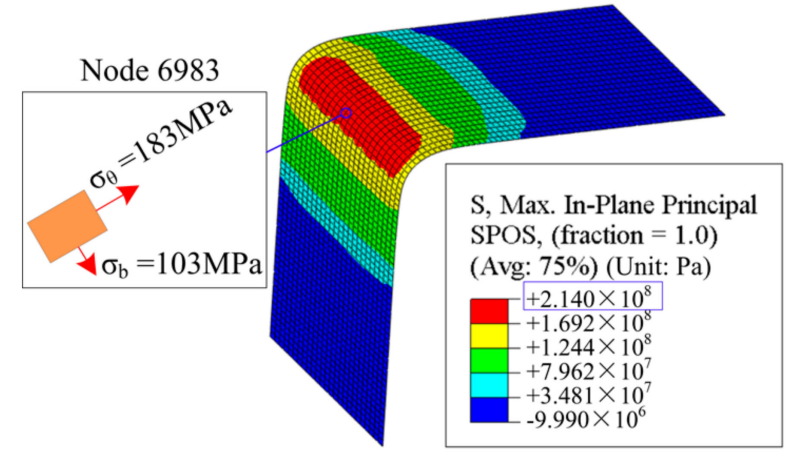

(a)

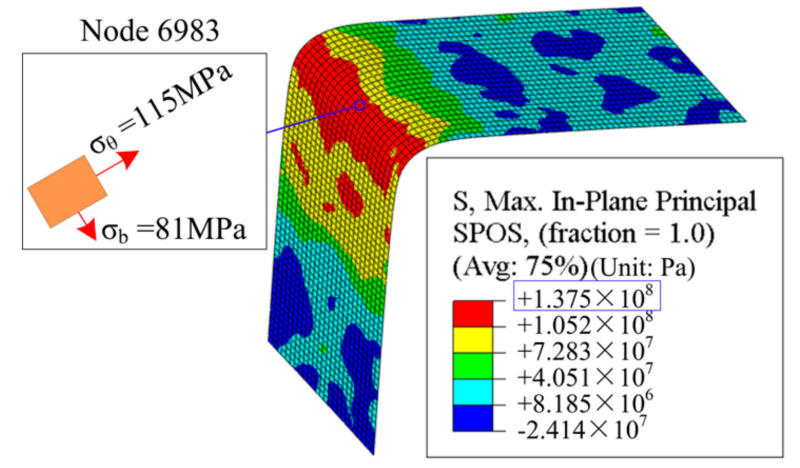

(c)

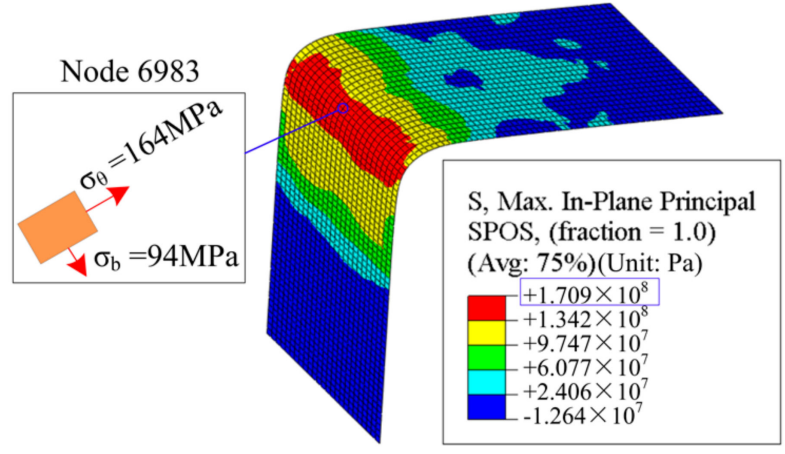

(b)

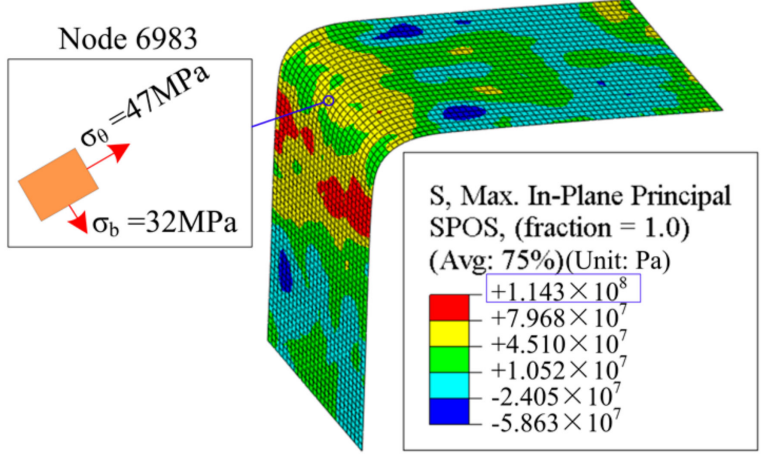

(d)

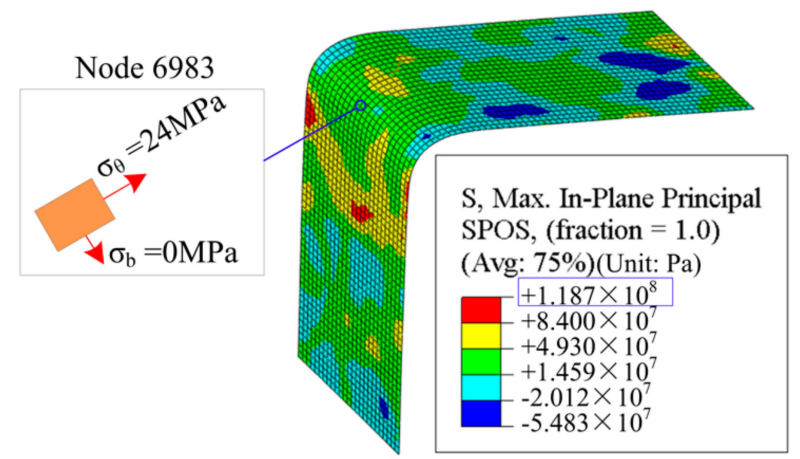

(e)

Figure 15. Stress distribution on the external surface under (a) quasi-static stamping or a discharge voltage of (b) $5 \mathrm{kV}$, (c) $6 \mathrm{kV}$, (d) $7 \mathrm{KV}$, and (e) $7.5 \mathrm{kV}$.

The distribution of tangential stress on the inner layer of sheet metal at different discharge voltages is shown in Figure 16. Larger discharge voltages result in a more uneven distribution of tangential compressive stress in the inner layer, whereas the maximum tangential compressive stress is smaller and occurs at the straight-edge area of the metal sheet. 


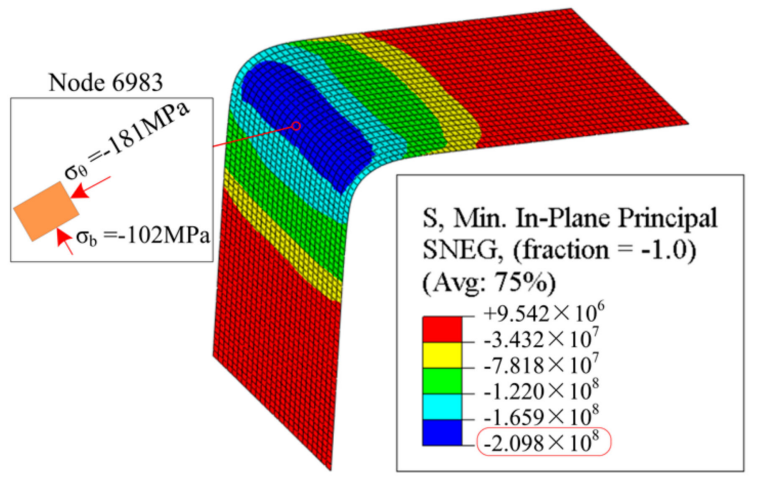

(a)

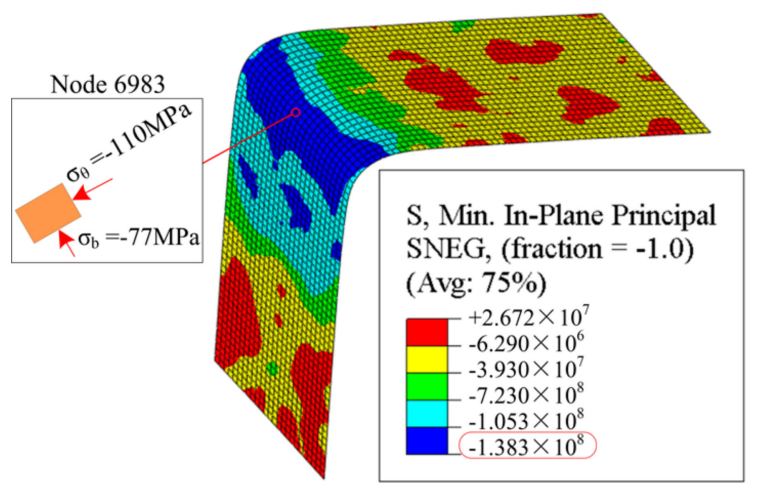

(c)

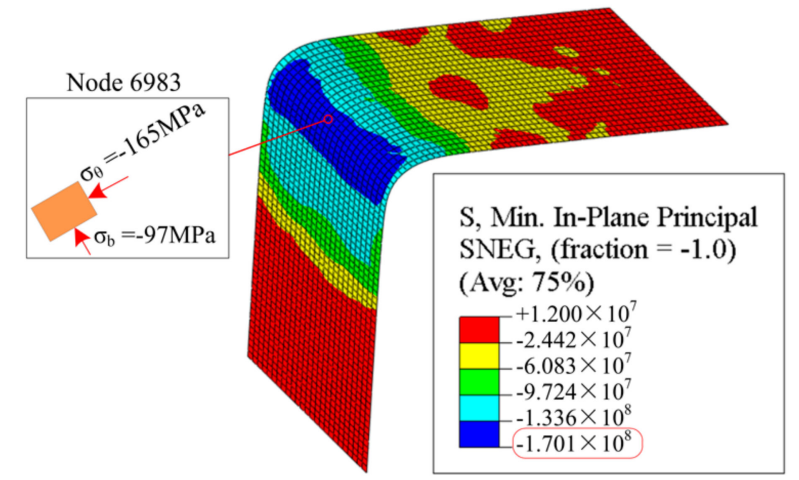

(b)

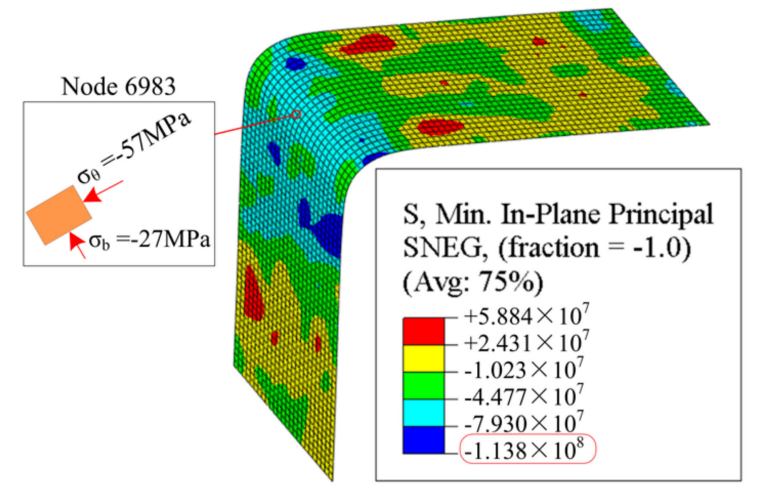

(d)

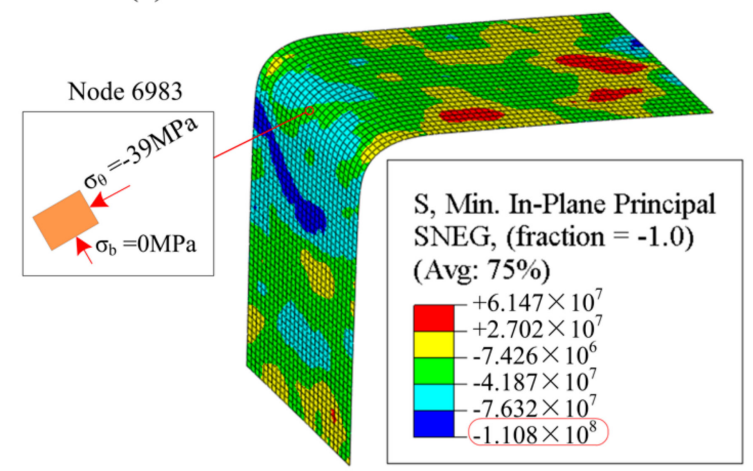

(e)

Figure 16. Stress distribution on the inner surface under (a) quasi-static stamping or a discharge voltage of (b) $5 \mathrm{kV}$, (c) $6 \mathrm{kV}$, (d) $7 \mathrm{kV}$, and (e) $7.5 \mathrm{kV}$.

Figure 17 shows the changes of elastic strain energy and plastic dissipation energy with time during the quasi-static stamping and EMF process. The greater the elastic strain energy, the larger the springback. As shown in Figure 17a, the elastic strain energy and plastic dissipation energy after quasi-static stamping are $0.0985 \mathrm{~J}$ and $2.24789 \mathrm{~J}$, respectively. As the discharge voltage increases, the plastic dissipation energy increases, while the elastic strain energy decreases. Thus, the springback angle should decrease more rapidly with the increasing of discharge voltage after the EMF. 


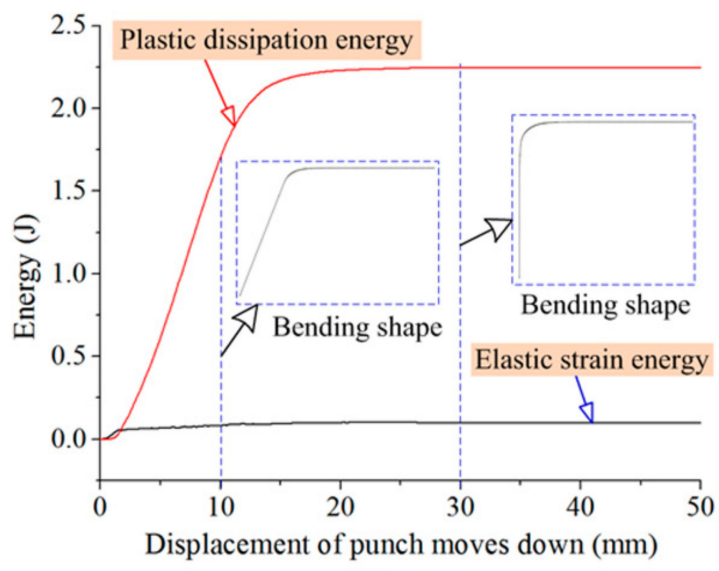

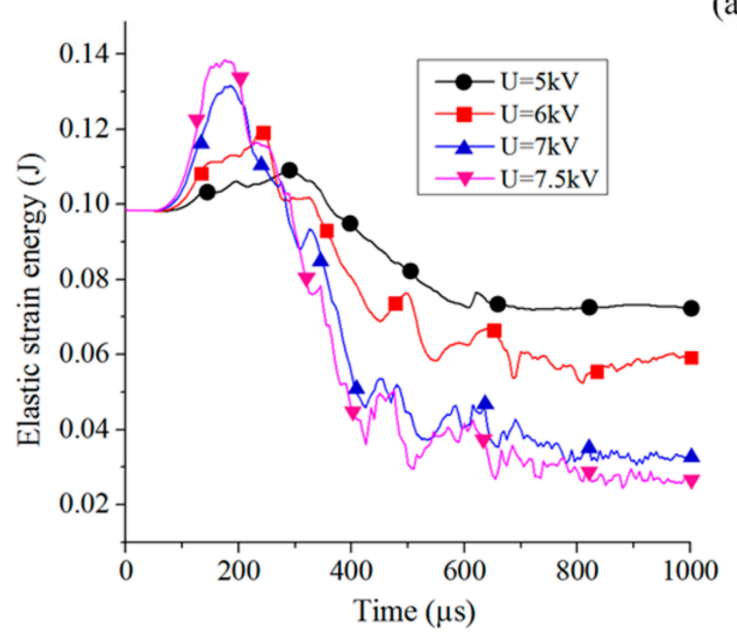

(b)

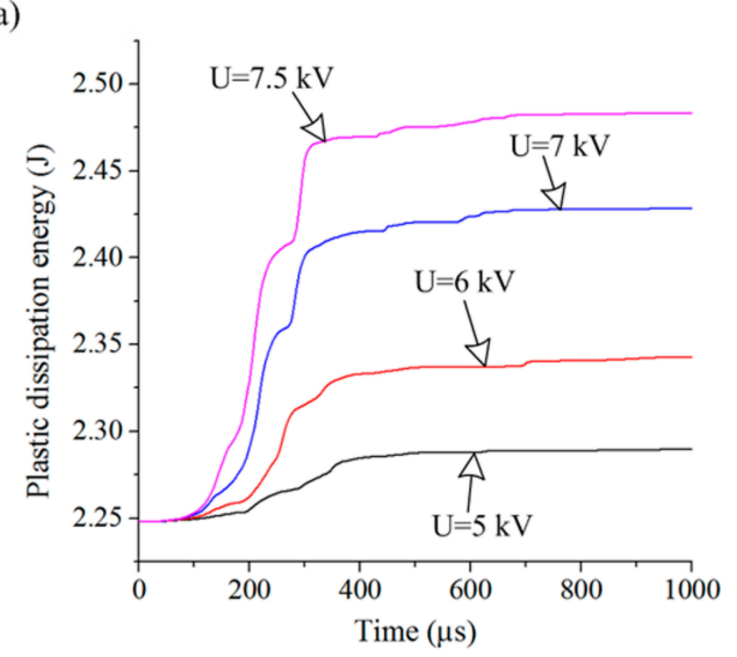

(c)

Figure 17. Changes of energy during stamping and electromagnetic forming (EMF) (a) quasi-static stamping, (b) elastic strain energy by EMF, and (c) plastic dissipation energy by EMF.

The tangential tensile stress, compressive stress, and elastic strain energy all decrease significantly after coil discharge, as shown in Figures 14-17, due to the springback of the metal sheet being related to the bending moment produced by the tangential stress in the bending region. Therefore, a smaller tangential stress in the bending region results in a smaller bending moment and a smaller springback angle. Moreover, the smaller the elastic strain energy, the smaller the springback. Figure 18 shows the springback angle with various discharge voltages. 


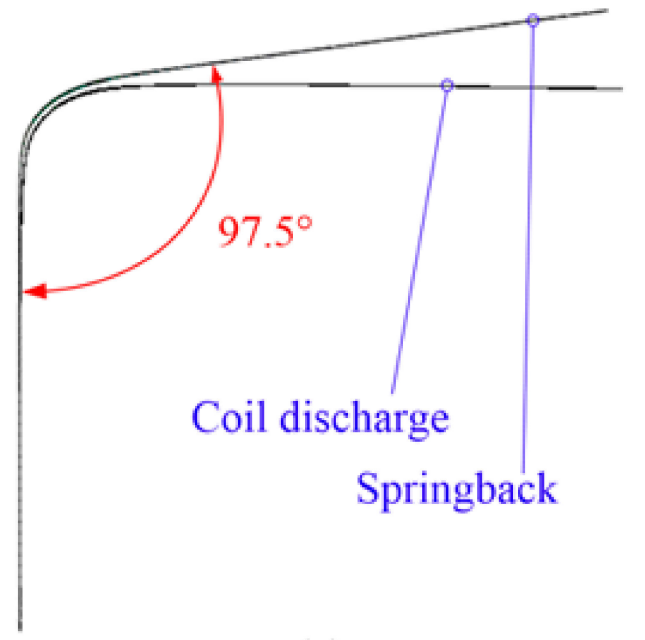

(a)

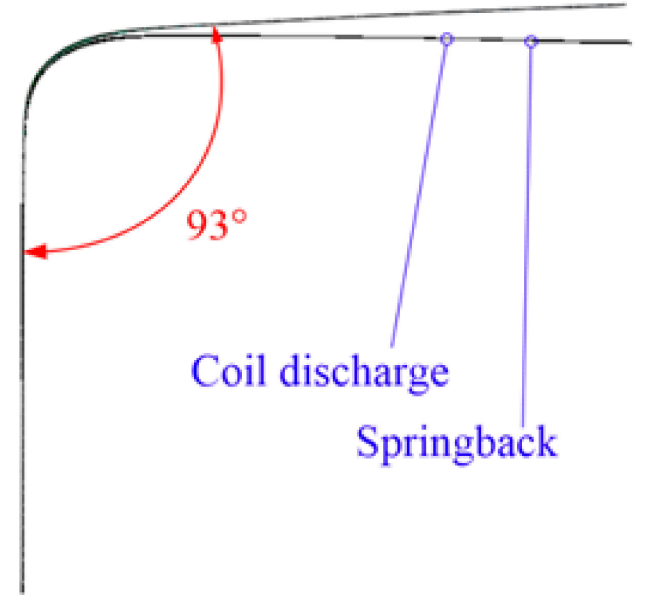

(c)

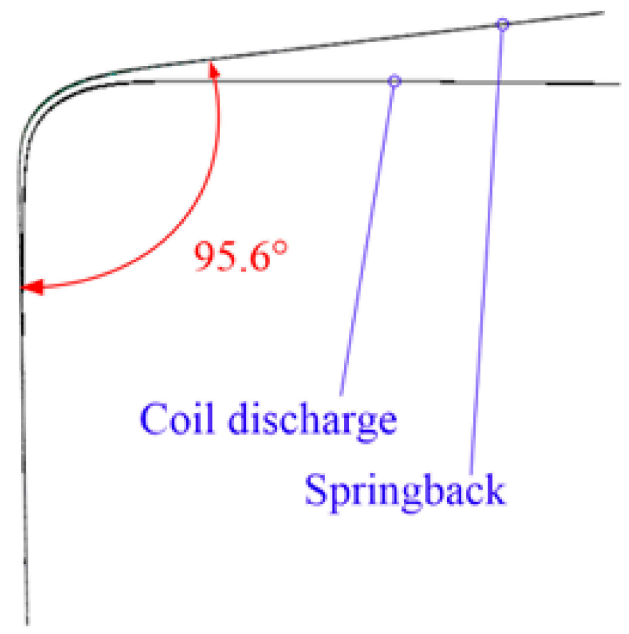

(b)

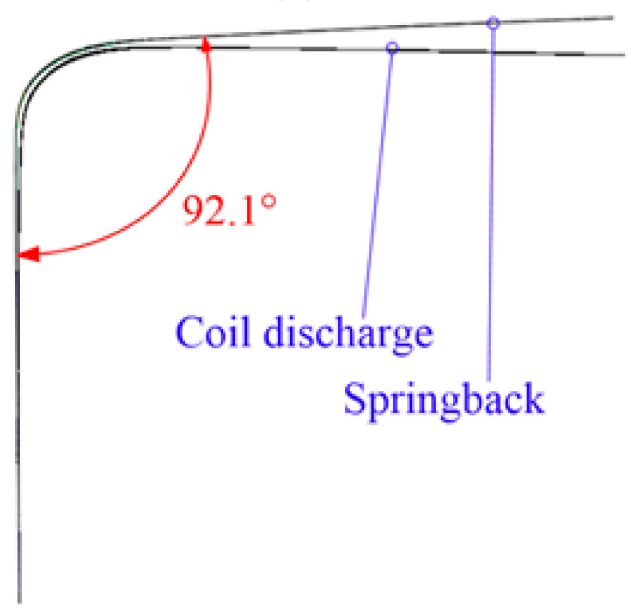

(d)

Figure 18. Springback angle from the front view after a coil discharge of (a) $5 \mathrm{kV}$, (b) $6 \mathrm{kV}$, (c) $7 \mathrm{kV}$, and (d) $7.5 \mathrm{kV}$.

Figure 19 shows the effect of sheet thickness $(t)$ on the springback angle. For the quasi-static stamping, the smaller the sheet thickness, the larger the springback angle that can be obtained. This satisfies the traditional plastic deformation law. However, under the same condition of discharge voltage $\mathrm{U}=7.5 \mathrm{kV}$, the smaller the sheet thickness, the greater the reduction of springback angle between the quasi-static stamping and EMF. This is because the thinner sheet is more prone to deformation under same discharge condition. For the thicker sheet, a higher discharge voltage should be used. 


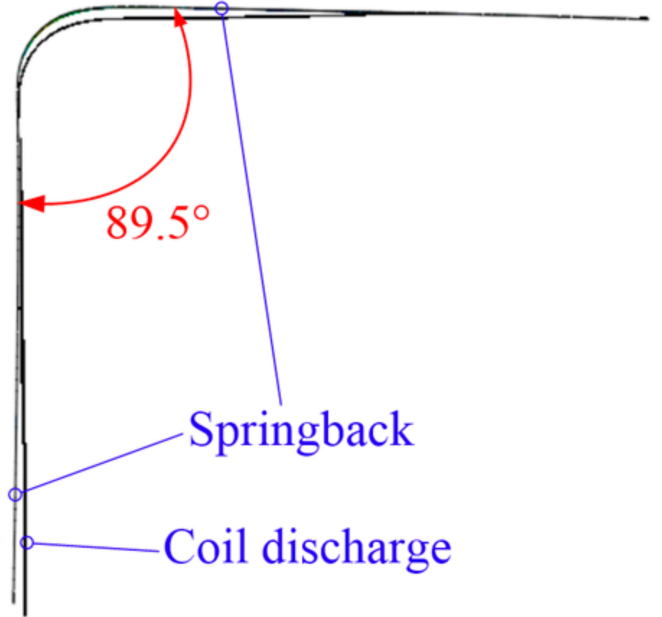

(a)

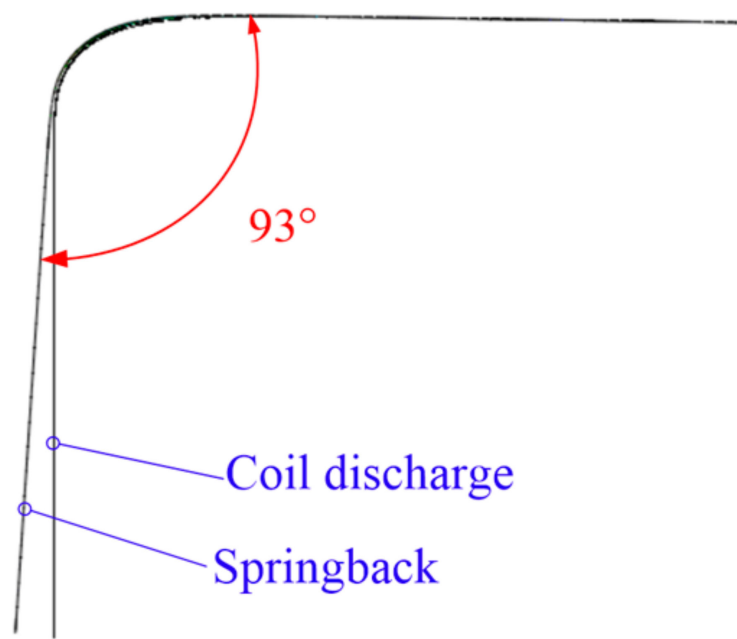

(b)

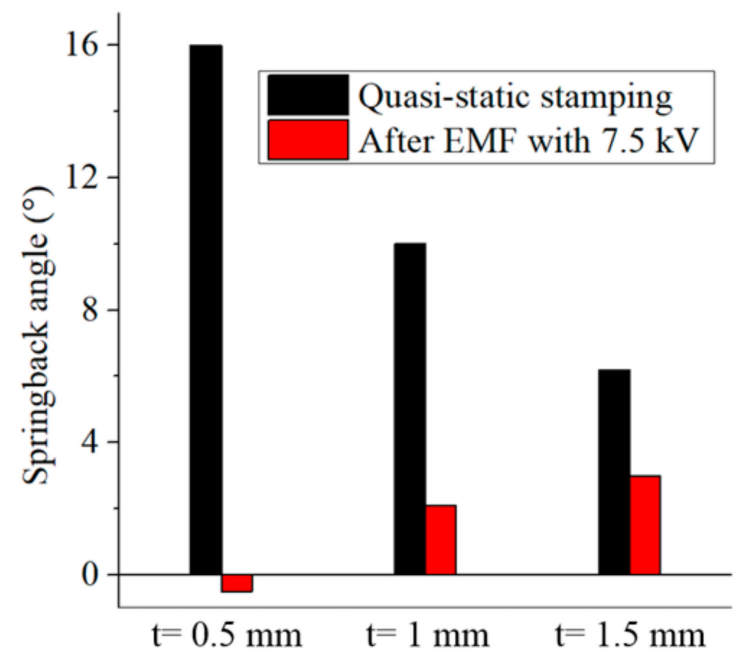

(c)

Figure 19. Springback angle with different sheet thickness: (a) the sheet thickness is equal to $0.5 \mathrm{~mm}$ and its deformation shape, (b) the sheet thickness is equal to $1.5 \mathrm{~mm}$ and its deformation shape, (c) comparison between the quasi-static stamping and EMF.

\section{Comparison of Experimental and Simulation Results}

The entire forming equipment is shown in Figure 20, including the 200-kJ electromagnetic forming machine and 100-T hydraulic press. The 200-kJ electromagnetic forming machine included an energy storage device, trigger device, control device, and measurement device. The measurement device used a Lovros coil, and an oscilloscope was used to measure the current of the magnetic pulses flowing through the coil. Figure 20b shows the forming die and coil mounted on the 100-T hydraulic press. The blankholder and die are made of non-metal. The punch is made of metal. During the forming process, the punch first moves downwards and bends the sheet metal; then, the punch is fixed, and the coil is discharged at the end of the sheet metal to reduce springback. 


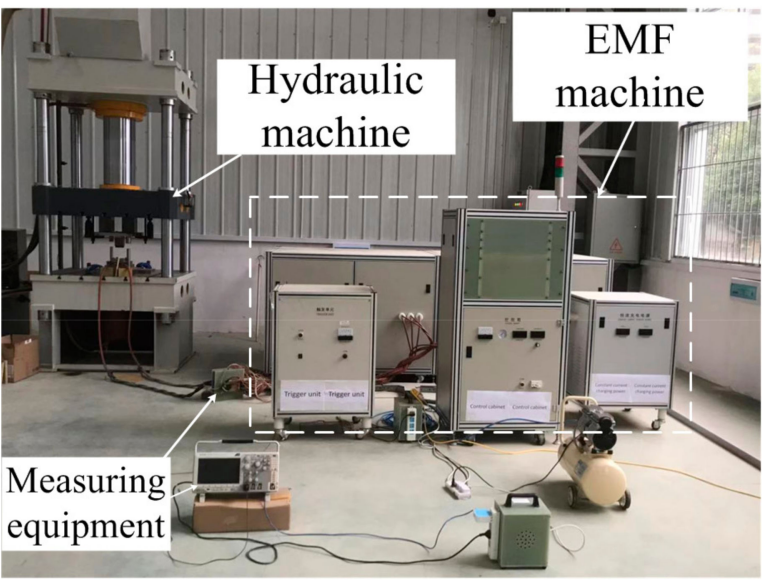

(a)

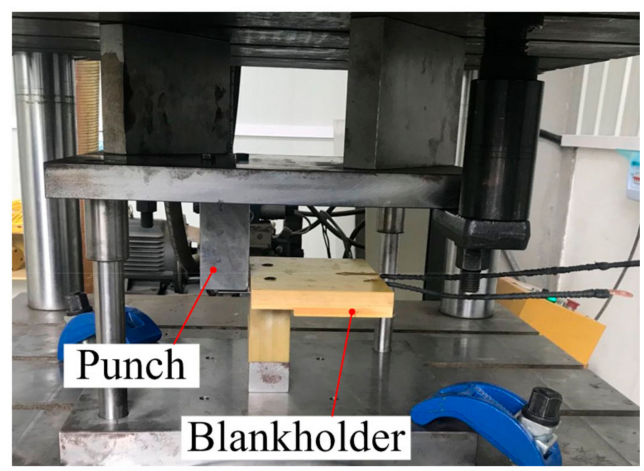

(b)

Figure 20. Experimental setup: (a) EMF machine and measurement equipment, (b) metal forming module.

The springback values obtained experimentally for different coil discharge voltages are presented in Figure 21a, and the experimental springback angles are compared to the simulated values in Figure 21b. With the discharge voltage increases, the springback angle gradually decreases. The simulation results can better describe the changes in the springback angle of the metal sheet after the coil discharges.

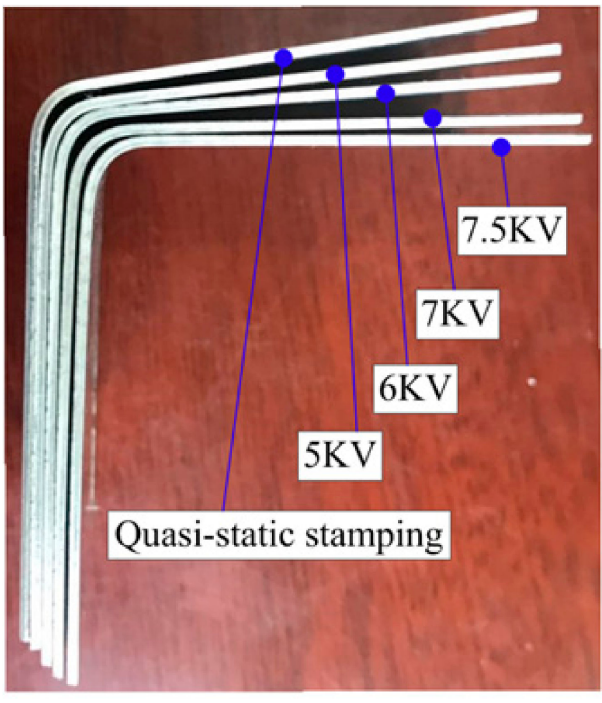

(a)

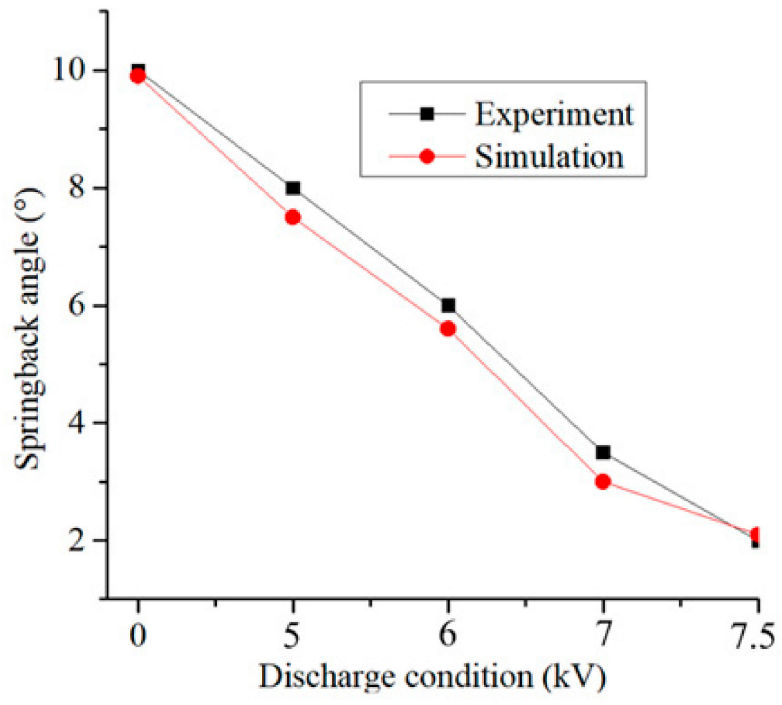

(b)

Figure 21. Comparison of (a) experimental (b) simulation results for the deformation profile and springback angle.

\section{Conclusions}

A new springback control method for L-shaped parts using EMF was proposed in this paper. The main conclusions are as follows.

(1) The proposed EMF simulation method is suitable for shell elements, and the simulation results are consistent with experimental results.

(2) Both the tangential stress at the sheet bending region and the elastic strain energy on the sheet decrease with the increasing of discharge voltage. Eventually, as the discharge voltage increases, the springback angle is greatly reduced. 
(3) During the forming process, the gap between the blank holder and the die must be larger than the thickness of the sheet, which helps the sheet undergo certain dynamic movements along the $\mathrm{X}$ and $\mathrm{Z}$-axis after the coil discharges. The smaller the sheet thickness, the greater the reduction of the springback angle between the quasi-static stamping and EMF that can be obtained.

Author Contributions: Writing—review and editing, X.C.; writing-original draft preparation, A.X.; validation, Z.D. and Z.Y.; investigation, H.Y. The manuscript was written by X.C. and A.X.; with support from all co-authors. All authors have read and agreed to the published version of the manuscript.

Funding: This work was supported by the National Natural Science Foundation of China (Grant Number: 51775563 and 51405173), Innovation Driven Program of Central South University (Grant number: 2019CX006), Guangzhou Science and Technology Plan Project (201707010472), State Key Laboratory of Materials Processing and Die \& Mold Technology, Huazhong University of Science and Technology (No.P2017-013), the Project of State Key Laboratory of High Performance Complex Manufacturing, Central South University (ZZYJKT2017-03), and the Open Research Fund of State Key Laboratory of High Performance Complex Manufacturing, Central South University (No. Kfkt2018-02).

Conflicts of Interest: The authors declare no conflict of interest.

\section{References}

1. Egea, A.J.; Rojas, H.A.; Celentano, D.J.; Travieso-Rodríguez, J.; Fuentes, J.L. Electroplasticity assisted bottom bending process. J. Mater. Process. Technol. 2014, 214, 2261-2267. [CrossRef]

2. Egea, A.J.; Rojas, H.A.; Celentano, D.J.; Peiró, J.J. Mechanical and metallurgical changes on 308L wires drawn by electropulses. Mater. Des. 2016, 90, 1159-1169. [CrossRef]

3. Psyk, V.; Risch, D.; Kinsey, B.L.; Tekkaya, A.E.; Kleiner, M. Electromagneticforming-A review. J. Mater. Process. Technol. 2011, 211, 787-829. [CrossRef]

4. Imbert, J.M.; Winkler, S.L.; Worswick, M.J.; Oliveira, D.A.; Golovashchenko, S. The effect of tool-sheet interaction on damage evolution in electromagnetic forming of aluminum alloy sheet. J. Eng. Mater. Technol. 2005, 127, 145-153. [CrossRef]

5. Li, F.Q.; Mo, J.H.; Li, J.J.; Zhou, H.Y. Formability of Ti-6Al-4V titanium alloy sheet in magnetic pulse bulging. Mater. Des. 2013, 52, 337-344. [CrossRef]

6. Seth, M.; Vohnout, V.J.; Daehn, G.S. Formability of steel sheet in high velocity impact. J. Mater. Process. Technol. 2005, 168, 390-400. [CrossRef]

7. Cui, X.H.; Mo, J.H.; Li, J.J.; Huang, L.; Zhu, Y.; Li, Z.W.; Zhong, K. Effect of second current pulse and different algorithms on simulation accuracy for electromagnetic sheet forming. Int. J. Adv. Manuf. Technol. 2013, 69, 1137-1146. [CrossRef]

8. Cui, X.H.; Mo, J.H.; Li, J.J.; Xiao, X.T.; Zhou, B.; Fang, J.X. Large-scale sheet deformation process by electromagnetic incremental forming combined with stretch forming. J. Mater. Process. Technol. 2016, 237, 139-154. [CrossRef]

9. Cui, X.H.; Mo, J.H.; Li, J.J.; Xiao, X.T. Tube bulging process using multidirectional magnetic pressure. Int. J. Adv. Manuf. Technol. 2017, 90, 2075-2083. [CrossRef]

10. Yu, H.P.; Li, C.F. Effects of current frequency on electromagnetic tube compression. J. Mater. Process Technol. 2009, 209, 1053-1059.

11. Shang, J.H. Electromagnetically Assisted Sheet Metal Stamping. Ph.D. Thesis, The Ohio State University, Columbus, OH, USA, 2006.

12. Liu, D.H.; Zhou, W.H.; Li, C.F. Springback control and deformation analysis for electromagnetically assisted bending of U-shaped parts. Chin. J. Nonferrous Met. 2013, 23, 3075-3082.

13. Sun, C. Deformation Analysis of U Shape Parts Formed by Electromagnetically Assisted Sheet Metal Bending. Master's Thesis, Harbin Institute of Technology, Harbin, China, 2009.

14. Iriondo, E.; Gutiérrez, M.A.; González, B.; Alcaraz, J.L.; Daehn, G.S. Electromagnetic impulse calibration of high strength sheet metal structures. J. Mater. Process. Technol. 2011, 211, 909-915. [CrossRef]

15. Iriondo, E.; Alcaraz, J.L.; Daehn, G.S.; Gutiérrez, M.A.; Jimbert, P. Shape calibration of high strength metal sheets by electromagnetic forming. J. Manuf. Process. 2013, 15, 183-193. [CrossRef] 
16. Woodward, S.; Weddeling, C.; Daehn, G.; Psyk, V.; Carson, B.; Tekkaya, A.E. Agile production of sheet metal aviation components using disposable electromagnetic actuators. In Proceedings of the 4th International Conference on High Speed Forming, Columbus, OH, USA, 9-10 March 2010; pp. 35-46.

17. Hu, J.H.; Ning, B.W.; Cai, H.; Huang, R.G. Experimental study on springback of aluminum alloy sheet by electromagnetic forming. J. Plast. Eng. 2013, 20, 104-108.

18. Cui, X.H.; Yu, H.L.; Wang, Q.S. Electromagnetic impulse calibration in V-shaped parts. Int. J. Adv. Manuf. Technol. 2018, 97, 2959-2968. [CrossRef]

19. Cui, X.H.; Zhang, Z.W.; Yu, H.L.; Xiao, X.T.; Cheng, Y.Q. Springback Calibration of a U-Shaped Electromagnetic Impulse Forming Process. Metals 2019, 9, 603. [CrossRef]

20. Cui, X.H.; Zhang, Z.W.; Du, Z.H.; Yu, H.L.; Qiu, D.Y.; Cheng, Y.Q. Inverse bending and springback-control using magnetic pulse forming. J. Mater. Process. Technol. 2020, 275, 116374. [CrossRef]

21. Cui, X.H.; Li, J.J.; Mo, J.H.; Fang, J.X.; Zhou, B.; Xiao, X.T.; Feng, F. Incremental electromagnetic-assisted stamping (IEMAS) with radial magnetic pressure: A novel deep drawing method for forming aluminum alloy sheets. J. Mater. Process. Technol. 2016, 233, 79-88. [CrossRef]

22. Cui, X.H.; Mo, J.H.; Han, F. 3D Multi-physics field simulation of electromagnetic tube forming. Int. J. Adv. Manuf. Technol. 2012, 59, 521-529. [CrossRef]

23. Cui, X.H.; Qiu, D.Y.; Jiang, L.N.; Yu, H.L.; Du, Z.H.; Xiao, A. Electromagnetic sheet forming by uniform pressure using flat spiral coil. Materials 2019, 12, 1963. [CrossRef]

24. Cao, Q.L.; Han, X.T.; Lai, Z.P.; Xiong, Q.; Zhang, X.; Chen, Q.; Xiao, H.X.; Li, L. Analysis and reduction of coil temperature rise in electromagnetic forming. J. Mater. Process. Technol. 2015, 225, 185-194. [CrossRef]

(C) 2020 by the authors. Licensee MDPI, Basel, Switzerland. This article is an open access article distributed under the terms and conditions of the Creative Commons Attribution (CC BY) license (http://creativecommons.org/licenses/by/4.0/). 